\title{
Foraging behavior of northern fur seals closely matches the hierarchical patch scales of prey
}

\author{
Kelly J. Benoit-Bird ${ }^{1, *}$, Brian C. Battaile ${ }^{2}$, Chad A. Nordstrom ${ }^{2}$, Andrew W. Trites ${ }^{2}$ \\ ${ }^{1}$ College of Earth, Ocean, and Atmospheric Sciences, Oregon State University, 104 CEOAS Administration Building, \\ Corvallis, Oregon 97331, USA \\ ${ }^{2}$ Marine Mammal Research Unit, University of British Columbia, Room 247, AERL, 2202 Main Mall, Vancouver, \\ British Columbia V6T 1Z4, Canada
}

\begin{abstract}
Marine prey often occur in hierarchical mosaics whereby small, high-density patches are nested inside of larger, lower density aggregations. We tested the extent to which the foraging behavior of a marine predator (northern fur seal Callorhinus ursinus) could be explained by the hierarchical patch structure of a dominant prey species (juvenile walleye pollock Theragra chalcogramma) in the eastern Bering Sea. Comparing the movements of satellite-tracked fur seals with ship-based acoustic surveys of prey revealed that fur seals did not randomly search for prey, but instead showed deviations in the distribution of step-lengths (distances between their foraging patches) corresponding to the distances between aggregations of prey. Scales of prey distribution varied between Bering Sea shelf and deep-water slope habitats, while spatial scale distributions of fur seals showed corresponding changes, indicating that their search strategies were not innate patterns decoupled from the environment. Fur seals tended to avoid the smallest prey patches in both shelf and slope habitats. They also avoided prey patches that were separated by large distances. Fur seals responded to several levels of prey patchiness simultaneously, resulting in strong correlations between predator and prey over the entire range of aggregation scales observed in juvenile pollock. Our results indicate that, despite having a varied diet, fur seal foraging paths were defined by juvenile pollock aggregations. The presence of hierarchical, scale-dependent aggregation in both predator and prey provides new insights into fur seal behavior and a means to predict the dynamics of their interactions with prey.
\end{abstract}

KEY WORDS: Patchiness - Spatial scale - Predator-prey - Foraging behavior - Hierarchical · Northern fur seal $\cdot$ Juvenile walleye pollock

\section{INTRODUCTION}

Spatial heterogeneity of physical characteristics and organisms is a general phenomenon in the ocean (Steele 1978). This patchiness of biota can be exhibited across a broad range of scales, with distinct aggregations occurring at scales ranging from less than a meter (Davis et al. 1991, Dekshenieks et al. 2001) to hundreds of kilometers (Haury et al. 1978, Mackas et al. 1985). Aggregations in a system often exist across a range of scales in a hierarchical mosaic ( $\mathrm{Wu}$ \& Loucks 1995), with small, high-density patches nested inside of larger, lower density aggregations (Kotliar \& Wiens 1990). Spatial patterns of organisms at a range of scales have been shown to have significant ecosystem effects including the cycling of elements and population dynamics (Levin 1992), as well as the mechanisms structuring communities (Benoit-Bird \& McManus 2012).

Many pelagic predators feed specifically on aggregated prey (Benoit-Bird \& Au 2003). As a consequence, patchiness and scale have become essential concepts in studies of marine predator-prey interactions (Sih 1982, Hunt \& Schneider 1987, Rose \& 
Leggett 1990, Fauchald 2009). The spatial distribution of prey items in the ocean has been shown to have strong effects on the energetic gains and costs of foraging (Tiselius et al. 1993), foraging success and overall predator performance (Boyd 1996), growth and survival (Lasker 1975, Beyer 1995), as well as predator behavior (Benoit-Bird 2009, Benoit-Bird \& $\mathrm{Au}$ 2009). To be successful, a predator must track changing prey patterns and respond to complex heterogeneity at different spatial and temporal scales (Russell et al. 1992, Mason \& Brandt 1996).

The eastern Bering Sea shelf and the adjacent deep waters form a highly productive ecosystem (Springer et al. 1996, Mizobata et al. 2008). Euphausiids Thysanoessa spp. and juvenile walleye pollock Theragra chalcogramma are 2 abundant species of prey in this ecosystem that aggregate at scales of a few meters (Benoit-Bird et al. 2011) up to tens (Decker \& Hunt 1996) and hundreds of kilometers (Sigler et al. 2012). At the edge of the Bering Sea shelf, St. George and St. Paul islands (part of the Pribilof Archipelago) serve as breeding sites for one of the largest concentrations of seabirds in the North Pacific (Hickey \& Craighead 1977), as well as the largest breeding population of northern fur seals Callorhinus ursinus; a population which is currently in decline (Towell et al. 2011). A growing colony of fur seals with about a $75 \%$ percent smaller population was recently established about $200 \mathrm{~km}$ to the southeast on Bogoslof Island, adjacent to deep waters north of the Aleutian arc (Towell \& Ream 2011).

During the summer, lactating northern fur seals are central place foragers (Orians \& Pearson 1979), making extended (1-14 d) foraging trips of hundreds of kilometers between short (1-3 d) stays on land to nurse their pups (Gentry \& Holt 1986, Nordstrom et al. 2013). Females breeding in the southeastern Bering Sea feed mainly on juvenile walleye pollock, squid, forage fish, and vertically migrating mesopelagic fish (Sinclair et al. 2008, 2011, Call \& Ream 2012). They feed in bouts interspersed along their travel path, diving to depths of up to $200 \mathrm{~m}$ (Gentry et al. 1986, Loughlin et al. 1987, Goebel et al. 1991). Female northern fur seals tend to forage in different habitats depending upon their home rookery (Robson et al. 2004). Prey selection and diving bout characteristics (Kooyman et al. 1976, Goebel et al. 1991, Kuhn et al. 2010) vary according to foraging habitats (Loughlin et al. 1987, Goebel et al. 1991, Sinclair et al. 1994, Antonelis et al. 1997, Zeppelin \& Ream 2006).

Our goal was to describe the spatial scales of foraging behavior exhibited by northern fur seals and compare these with the scales of aggregation observed in an important prey group, juvenile pollock, to determine at which scales and conditions fur seals respond to their prey. We hypothesized that the spatial scales of both predator and prey could be hierarchically nested, and examined the scales of both positive regions (patches) and negative ones (spaces or gaps between patches) to determine the coherence of these predator and prey spatial scales. While ecosystems with hierarchical patch systems are common (Wu \& Loucks 1995), relatively few studies have focused on foraging patterns or predator-prey interactions in hierarchical patch systems (O'Neill et al. 1991, Russell et al. 1992, Ives et al. 1993, Fauchald 1999, Fauchald et al. 2000, Fauchald \& Tveraa 2006).

Understanding how predators effectively respond to prey spatial heterogeneity requires realistic conceptualizations of patch structure within the habitat. Multi-layered patch systems involve complexities that result in deviations from the foraging predictions generated by simple, single-level patch models (Kotliar \& Wiens 1990). Spatial relationships between predators and their prey have been examined using a variety of approaches. These include synoptic surveys of the abundance and distribution of predators and prey (Fauchald et al. 2000, Benoit-Bird et al. 2011), tracking of individual predators coupled with spatially and temporally overlapping measurements of prey (Sims \& Quayle 1998), or remote tracking of predators with proxy measures of foraging attempts in the absence of prey measures (Weimerskirch et al. 2007); each of which presents particular challenges in interpreting nested scales of patchiness. In our study, we used high-resolution remote tracking to observe spatial scales of movement of fur seals independently of the scales of spatial distribution of a key prey group, juvenile pollock, which we assessed using fisheries acoustics techniques. We thereby relied on large sample sizes of fur seals and juvenile pollock to statistically identify relationships between spatial scales of predator and prey.

\section{MATERIALS AND METHODS}

As part of a large, interdisciplinary program (Bering Sea Project; Wiese et al. 2012), we combined tagging observations of northern fur seal behavior with at-sea sampling of prey fields. Fur seals were tagged with data logging instruments from mid-July to mid-September 2009 at 2 sites - St. Paul Island in the Pribilof Archipelago and Bogoslof Island just north of the Aleutian Arc (see Fig. 1). Prey data were 
collected from mid-July to mid-August 2009 in the contiguous area surrounding the breeding islands.

\section{Fur seals}

Tagging

We tagged 82 lactating northern fur seals on 2 islands in the eastern Bering Sea, St. Paul from 10 July to 19 September, 2009. Each animal was fitted with a Wildlife Computers Mk10-F tag, a Daily Diary tag, and a VHF transmitter (41 seals tagged on Bogoslof Island recorded 111 foraging trips; 41 seals tagged on St. Paul Island recorded 51 foraging trips). Tags were mounted dorsally along the centerline of the animal between the shoulder blades. Animals were recaptured for tag and data recovery after foraging trips. Further details of the instrument deployments and handling can be found in Nordstrom et al. (2013).

The Mk10-F was programmed to record GPS fixes every 15 min when the animal was at the surface. Individual seal behavior, tag placement, satellite locations and weather considerations resulted in GPS fixes occurring, on average, every $75 \mathrm{~min}$ for seals tagged on St. Paul Island and every 96 min for seals tagged on Bogoslof Island. The Daily Diary tag contained tri-axial (from the animal's frame of reference: anterior-posterior, dorsal-ventral, and lateral) accelerometers and magnetometers to record acceleration and the earth's magnetic field at $16 \mathrm{~Hz}$. In addition, the tags recorded depth and temperature at $1 \mathrm{~Hz}$, and time and date at $16 \mathrm{~Hz}$. Finally, tags included a wet/dry switch, which identified when animals hauled out on land, allowing us to accurately determine the start and end of each foraging trip (a complete track).

\section{Track reconstruction}

Geographic positions from the GPS and motion data from the accelerometers and magnetometers were combined to model the paths of the tagged animals and produce high-resolution tracks. First, all GPS points including the last and first points on land bookending the foraging trip were identified. Next, the acceleration and magnetometer sensors were standardized to read between -1 and +1 using linear regression and oriented to the right hand rule, so that a value of +1 was measured by the accelerometers when the front, top, or left side of the tag was facing the earth, and a value of +1 was measured by the magnetometers when the front, top, or left side of the tag was facing north and at the angle of inclination of the magnetic field. Reconstructed tracks were then calculated in a process akin to dead-reckoning using the algorithm presented by Wilson et al. (2007), with a few clarifications.

The earth's gravitational field, or 'static' acceleration, in each dimension was estimated as a $2 \mathrm{sec}$ running mean of acceleration for each channel. The running mean was then subtracted from its respective channel to estimate the 'dynamic' acceleration due to animal movement. Speed was estimated as the running sum of the 'dynamic' portion of the anterior-posterior acceleration channel, and then converted to animal velocity using linear scaling with a minimum of 0 and a maximum of $3.5 \mathrm{~m} \mathrm{~s}^{-1}$ (the approximate maximum speed of an adult female northern fur seal). When the lateral accelerometer channel indicated that an animal was resting, the speed was set to 0 .

The inclination and declination of the earth's magnetic field was calculated given the date, latitude and longitude using the World Magnetic Model 2010 Calculator from the British Geological Survey. We used a single declination and inclination value for each island as these values are relatively consistent over the geographic range covered by the tagged seals. Finally, we georeferenced the raw dead-reckoning tracks (Wilson et al. 2007), by forcing the tracks through all known GPS relocations starting and ending with those on land. Georeferencing adjusted the reconstructed pseudotracks for errors (such as currents) that are not measurable by the tags, as well as other errors that are inherent in the limitations of the technology and methodology.

To test the degree of spatial errors introduced by track reconstruction relative to GPS locations only, we calculated the amount of resizing that was necessary for the final location of each reconstructed track segment (e.g. the path between 2 GPS locations) to match the corresponding GPS location as a percentage of the total distance between the starting and ending points of the segment. For animals tagged at both islands, these estimates were normally distributed about zero. Approximately half of all track segments contracted or expanded $<10 \%$ to match the GPS locations, $\sim 70 \%$ of the track segments changed by $<20 \%$, and $\sim 95 \%$ of all track segments changed by $<50 \%$. Linear regression showed that the amount of contraction and expansion in percentage terms was unaffected by the time between GPS locations. Thus, these estimates of track changes provide an 
upper bound on the errors of scale associated with measures made in each track segment, independent of scale.

\section{Patches}

We used areas of restricted movements of fur seals, or patches, to quantify the spatial scales of fur seal behavior. Tortuosity is a measure of the straightness of an animal's swimming path. It is often used in animal tracking studies to describe animal movement paths and to distinguish between behavioral states, such as transiting, searching, and foraging (Morales et al. 2004). The tortuosity of foraging paths represents animal reactions to landscape heterogeneity in which animals translate environmental stimuli into movements (Crist et al. 1992, With 1994). Errors in calculating animal velocity and absolute orientation do not affect calculations of tortuosity; thus, reconstructed tracks such as those available for fur seals are useful in assessing the multi-scale tortuosity of complete animal tracks without bias for scale (Wilson et al. 2007).

To identify spatial patterns in fur seal retention, we used a 10-point running calculation of tortuosity of the $1 \mathrm{~Hz}$ reconstructed track locations. Tortuosity was calculated as the sum of the distances between 10 adjacent locations along a track (that is, the total distance traveled) divided by the straight line distance between the first and last of those 10 positions. A straight-line path results in a tortuosity value of 1 , while higher values represent higher degrees of turning. Using the 10-point calculation smoothed out isolated spikes in the data, while allowing the retention of fine-scale information.

We used patterns in tortuosity values to identify 'patches' or regions where a fur seal repeatedly turned to remain in a localized area. First, we set a threshold tortuosity value of 1.5 , representing approximately the upper quartile of all tortuosity values measured. To be identified as a patch, 5 adjacent tortuosity values (encompassing a total of 15 seconds of data) had to exceed the threshold tortuosity of 1.5. Points in the running tortuosity calculation with values above the threshold were then added to the patch if no more than 2 values lower than the threshold separated each point from a patch. Gaps were defined as 3 or more points in a row with tortuosity values <1.5. As with patches, points were added to this gap if they were separated from the gap by $\leq 2$ points with values $>1.5$. The distribution of gap sizes was bi-modal with the cutoff of the lower of the modes at $\sim 100 \mathrm{~m}$. To identify aggregations of patches, those separated by gaps $\leq 100 \mathrm{~m}$ were grouped into 'superpatches'. The horizontal size of identified patches and superpatches was measured as the distance between the first and last point within the feature.

To determine the effects of our parameter selection in identifying areas of fur seal retention, we conducted sensitivity analyses on the threshold tortuosity (1.25-2.50) and the number of points above the tortuosity threshold used to define a patch (5-20 points). Increasing either of these values decreased the number of patches detected in each track, but did not significantly affect the horizontal size of patches that were detected. Decreasing the tortuosity threshold below 1.5 increased the number of patches detected and significantly decreased the size of patches detected. The combination of threshold tortuosity and minimum contiguous points identified the greatest number of patches without changing the horizontal size distribution of the identified patches.

\section{Foraging habitat}

To identify the foraging habitat of fur seals, horizontal habitat use kernels were generated for all tracked individuals from each island using the locations of solitary patches and superpatches. Each putative foraging location was weighted by the amount of time spent within it. Adaptive kernels were optimized by least-squares cross validation (Worton 1989) using analysis grid cells of $100 \mathrm{~m}$ before being smoothed at a scale of $20 \mathrm{~km}$. The $95 \%$ utilization contour was used to define the foraging area for each island, while the $75 \%$ kernel was used to define higher foraging effort areas, and the $50 \%$ kernels defined the core foraging area for each island.

To explore the effects of time of day, habitat use kernels were generated separately for daylight and dark periods, excluding all periods of nautical twilight. Data were gridded at $20 \mathrm{~km}$ resolution to statistically compare day and night kernels. The day and night kernel values at each grid point were classified from 0 to 3 (no use to $50 \%$ kernels) and subtracted from each other to generate a single distribution for each island. The hypothesis that each of these distributions was randomly distributed about zero was tested using chi-squared tests.

Tagging of seals lasted longer than the at-sea surveys of the prey field. To determine if there was an effect of these time periods, habitat use kernels were generated using only those tracks that were at least 
$75 \%$ within the at-sea effort time period (Bogoslof: 16 seals, 48 trips; St Paul: 13 seals, 21 trips). These were similarly classified and gridded for comparison to the full habitat use kernels using chi-squared tests. For all further analysis, only those fur seal tracks that temporally overlapped by at least $75 \%$ with at-sea sampling were included to facilitate comparison between data sets. This permitted full fur seal trips to be included while facilitating comparison between the predator and prey data sets.

To examine the horizontal scales of habitat used by each seal, habitat use kernels were generated separately for each individual. The $50 \%$ kernels for each individual were converted from area measures into estimates of equivalent circular diameter to provide a measure of the largest scale retention areas for each fur seal.

Vertical habitat use by seals was examined by analyzing the maximum depth of each fur seal patch as a function of solar angle. This made it possible to compare the effects of time across the large spatial areas and across the entire sampling period, despite large seasonal and latitudinal changes in the absolute time of the movements of the sun. A repeated measures ANOVA was used to examine the within-subjects effects of topographic zone and solar radiation angle (in $2^{\circ}$ increments) as well as the between-subjects effect of island and the interacting effects of these variables on the maximum depth within each patch. The analysis was repeated using solar angle categorized simply as day (center of the sun above the horizon), night (center of the sun $>12^{\circ}$ below the horizon), and twilight (center of the sun $<12^{\circ}$ below the horizon). Fewer bins increased the number of samples per category and thus increased the power of the analysis.

\section{Foraging scale analysis}

The spatial scales of fur seal retention patterns were examined using repeated-measures ANOVAs (within-subjects effects = topographic zone, day/ night; between-subjects effect $=$ island). These were used to examine variation in the horizontal size of patches, the spacing between individual patches, superpatches, the spacing between superpatches, and the size of individual seal habitat use kernels.

Fur seal retention areas ranged from small, solitary patches to large superpatches. An ANOVA was used to explore the effects of time of day and zone on the number of patches that made up these fur seal retention areas. A chi-squared test was used to determine if there were significant differences in the frequencies of solitary patches versus superpatches by zone and time of day.

Following previous examinations of predator foraging behavior, we examined the distribution of step lengths - the distances swum between retention areas (e.g. 'flights' sensu Edwards et al. 2007). The distribution of these steps were assessed for their fit to a number of hypothesized distribution patterns (Lévy, exponential, gamma, log-logistic, log-normal, and Weibull) consistent with predictions from a variety of search patterns using a maximum likelihood approach implemented in EasyFit 5.5 (MathWave Technologies). Kolmogorov-Smirnov statistics were used to identify the most likely distribution from amongst the choices.

\section{Juvenile pollock}

Ship-based sampling of potential prey was conducted between mid-July and mid-August, using 2 chartered commercial fishing vessels. The sampling area roughly covered a $200 \mathrm{~km}$ radius around each colony. This area was chosen based on the foraging ranges observed for fur seals in previous studies (Gentry \& Holt 1986) and encompassed the entire track of all fur seal trips for Bogoslof Island individuals. For animals tagged at St. Paul Island, the sampling area completely covered the tracks of $>75 \%$ of individuals; for the remaining individuals, at least $80 \%$ of the track by time was encompassed by the sampling area. Sampling occurred along 141 transects, each $10 \mathrm{~km}$ long and stratified among 3 hydrographically distinct zones (Coachman 1986): (1) middle shelf, with bottom depths $<100 \mathrm{~m}_{i}(2)$ outer shelf, with bottom depths between 100 and $200 \mathrm{~m}$; and (3) slope, with depths $>200 \mathrm{~m}$. Each transect was continuously sampled with multifrequency acoustics (calibrated Simrad EK60 echosounders at 38, 70, 120, and $200 \mathrm{kHz}$ ). A single, depth-targeted net trawl provided the identity and size of nekton and macrozooplankton on each transect, using an $8 \times 8 \mathrm{~m}$ opening Marinovich midwater trawl fitted with a $3 \mathrm{~mm}$ codend mesh liner. Detailed methods for the ship-based sampling, including other data collected, are presented in Benoit-Bird et al. (2011).

Frequency differencing (De Robertis 2010, BenoitBird et al. 2011) was used to separate fish from other targets in the upper 5-100 $\mathrm{m}$ of the water column. As has been found in previous surveys of the same area (De Robertis 2010), net tow data indicated that fish were overwhelmingly dominated by juvenile walleye 
pollock in their first $2 \mathrm{yr}$ of life. All data not matching the 'fish' characteristics were masked out in the raw $38 \mathrm{kHz}$ echogram before additional analyses were conducted.

Myriax's Echoview Software, School Detection module was used to identify aggregations of pollock within the masked, full-resolution, $38 \mathrm{kHz}$ echograms. This approach looks for a minimum number of contiguous values in both the distance and depth directions above a set threshold (Barange 1994). For pollock, masked $38 \mathrm{kHz}$ data must have been greater than a threshold of $59 \mathrm{~dB}$ re $1 \mathrm{~m}^{-1}$, for at least $1 \mathrm{~m}$ vertically and $5 \mathrm{~m}$ along track (as corrected for beam effects; Diner 2001). This equated to $0.5 \mathrm{fish}^{-3}$ for the observed median size of juvenile pollock (McIntosh 2011). Data within the identified boundaries of each patch were thresholded at a value of $-85 \mathrm{~dB}$ re $1 \mathrm{~m}^{-1}$ and the minimum, maximum, and median depth, horizontal size, height, area, and horizontal distance to nearest neighboring patch were measured for each patch. Volume backscattering was converted to mean and maximum density of individuals using expected target strength (median pollock length for the transect along which the patch was detected) (Foote \& Traynor 1988, Traynor 1996). Each patch was then integrated to provide an estimate of the total biomass $(\mathrm{g})$ and total number of fish (ind.) per patch.

Variations in the characteristics of pollock patches were examined using a repeated-measures MANOVA with a within-subject effect of transect and between-subjects effects of day/night and zone, as well as the interactions of these effects. Bonferonni post-hoc analyses were used to examine the mean differences in these characteristics as a function of zone if a significant main effect was identified. The effects of zone and day/night on the total number of pollock patches detected per transect were tested using ANOVA. The distance to nearest neighboring patch in the upper $20 \mathrm{~m}$ of the water column during day and night was compared to the same measure over the entire water column at all times of day using $t$-tests. The effects of location within the slope region on horizontal scale of pollock patches and the spacing between them were examined by assigning each patch to the closest rookery before conducting an ANOVA.

Pollock patches were clustered in many echograms. The distribution of inter-pollock patch spacing was bi-modal, with a break between the modes at approximately $100 \mathrm{~m}$. To identify these larger scale aggregations of pollock ('superpatches'), we grouped all patches found $<100 \mathrm{~m}$ from neighboring patches. The horizontal size of each superpatch and the spacing between superpatches along a transect were measured. Because the transects were $10 \mathrm{~km}$ in length, measurements of inter-superpatch spacing could not be made at scales $>10 \mathrm{~km}$, and distances $>\sim 5 \mathrm{~km}$ may be underestimated in the data. Repeated-measures ANOVAs were used to look at the within-subject effect of transect and the between-subjects effects of day/night and zone as well as interactions of these effects on the horizontal size of pollock superpatches and the spaces between them.

\section{Horizontal scale comparisons}

To compare the scales at which pollock and fur seals were observed, only fur seal data collected within the study region and time period were included, in contrast to other analyses that had more permissive criteria for comparison. This reduced concerns about changes in space and time that could affect the outcome of the comparison when incorporating each full trip was not necessary. Wilcoxon signranks tests were used to compare the distributions of patch and gap sizes for each zone by island. This statistic tested whether the median difference between the 2 distributions is zero - in other words, whether there was a systematic offset in the distributions.

\section{RESULTS}

\section{Fur seal behavior}

The kernels, a description of the habitat over which the tagged seals from each island foraged, are shown in Fig. 1. There was no significant difference in kernels generated using all tracks versus just those that temporally overlapped with the at-sea sampling (St. Paul $\chi^{2}=1.89, \mathrm{p}=0.52 ;$ Bogoslof $\chi^{2}=0.94 ; \mathrm{p}=0.86$ )

Fur seals from Bogoslof Island, where the entire habitat is essentially deep slope, consistently foraged within $150 \mathrm{~km}$ of their rookery. The core foraging area for Bogoslof Island seals (50\% kernel) was a single, continuous region roughly centered on the island.

In contrast, fur seals from St. Paul Island traveled widely and had core foraging areas that were patchily distributed and spread over all 3 topographic zones. However, the 3 topographic zones were not used in proportion to their availability. Only $24 \%$ of St. Paul Island fur seal patches occurred over the middle shelf, a zone that accounted for $54 \%$ of the area within 200 $\mathrm{km}$ of the rookery. Deep water slope habitat accounted 


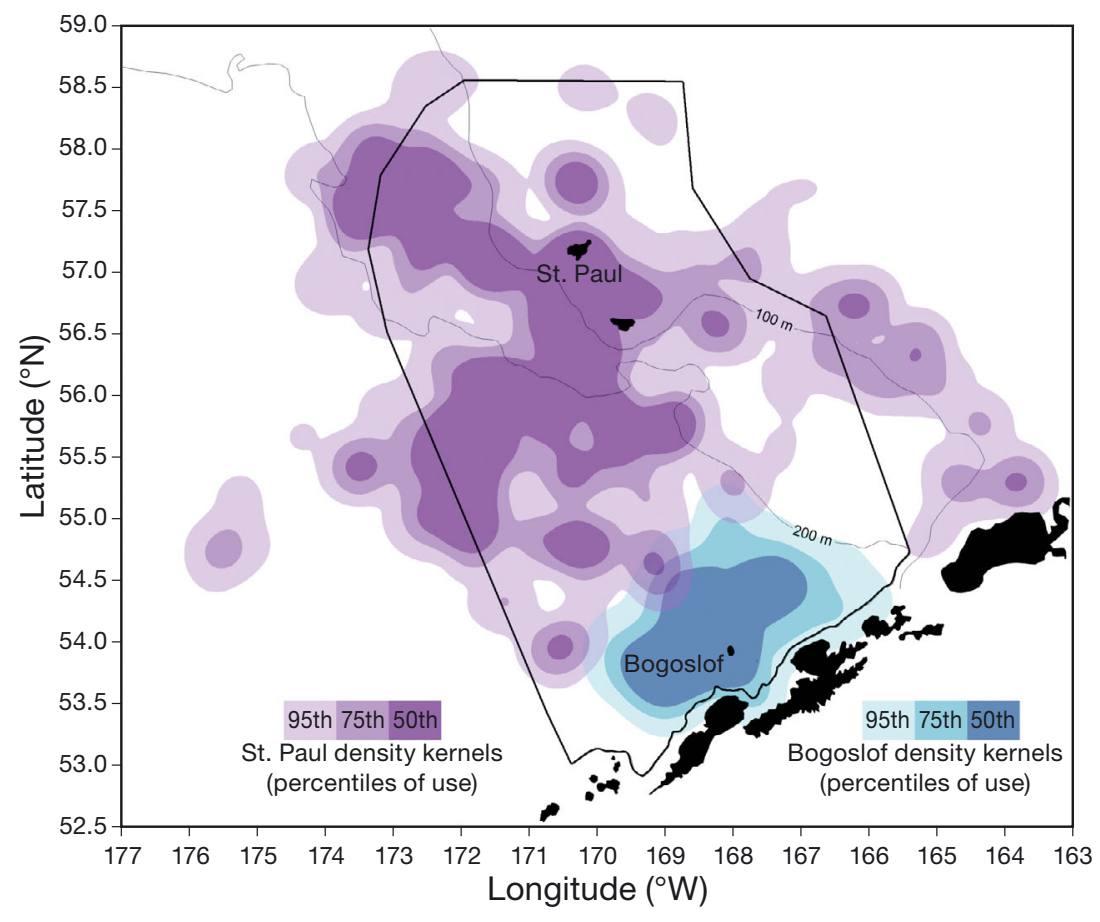

Fig. 1. Habitat use kernels for lactating northern fur seals Callorhinus ursinus tagged on St. Paul Island (purple) and Bogoslof Island (blue). Darker colors = areas of higher use. Kernels were generated using the location of solitary and grouped patches weighted by the time spent within them. The area covered by the at-sea surveys of habitat and prey is enclosed by a black line. The 100 and $200 \mathrm{~m}$ contours used to define zones are also shown
$1,76 ; p=0.007)$. For St. Paul seals, there was a significant effect of zone on foraging ratio (ANOVA: $F=6.33$; $\mathrm{df}=2,75 ; \mathrm{p}=0.02)$. The foraging ratios of St. Paul seals over the slope most closely resembled the foraging ratios for Bogoslof seals, though the distributions were still significantly different (ANOVA: $F=4.61, \mathrm{df}=1$, $\mathrm{p}=0.05$ )

There was a significant difference in total track duration between the 2 populations (ANOVA: $F=191.22$; $\mathrm{df}=$ $1,27 ; \mathrm{p}=0.004)$. However, there was no significant difference when the total time spent in patches within each track, rather than the ratio of this time to total trip duration, was compared between the different islands (ANOVA: $F=1.75$; $\mathrm{df}=1,76$; $\mathrm{p}=0.20$ ). Across all tracks, total time spent within patches averaged $51.4 \mathrm{~h}$ ( $\pm 13.7 \mathrm{SD})$.

Patches in fur seal tracks occurred at all times of the day and night for seals tagged on both islands; however, patches occurred disproportion- for only $15 \%$ of the area within $200 \mathrm{~km}$ of the rookery, but contained $44 \%$ of the St. Paul Island fur seal patches. Notably, only the outbound portions of trips by seals from St. Paul Island that ultimately went to slope waters had patches in the middle and outer shelves. Similarly, seals that ultimately went to the outer shelf had patches in the middle shelf only during the outbound portions of their trips. No patches were identified on the portions of trips that females made to return to the rookery. The only patch kernels found over the middle shelf within the area sampled for prey were immediately adjacent to the islands or associated with a distinct aggregation of juvenile pollock to the northwest of St. Paul Island (Benoit-Bird et al. 2011).

In addition to differences in how fur seals used the area around their rookeries, seals tagged at the different islands showed significant differences in their use of time. The total percentage of each track's time spent in patches (foraging ratio) was significantly higher for Bogoslof Island seals than St. Paul Island seals (Fig. 2; ANOVA: $F=7.65$; df $=$
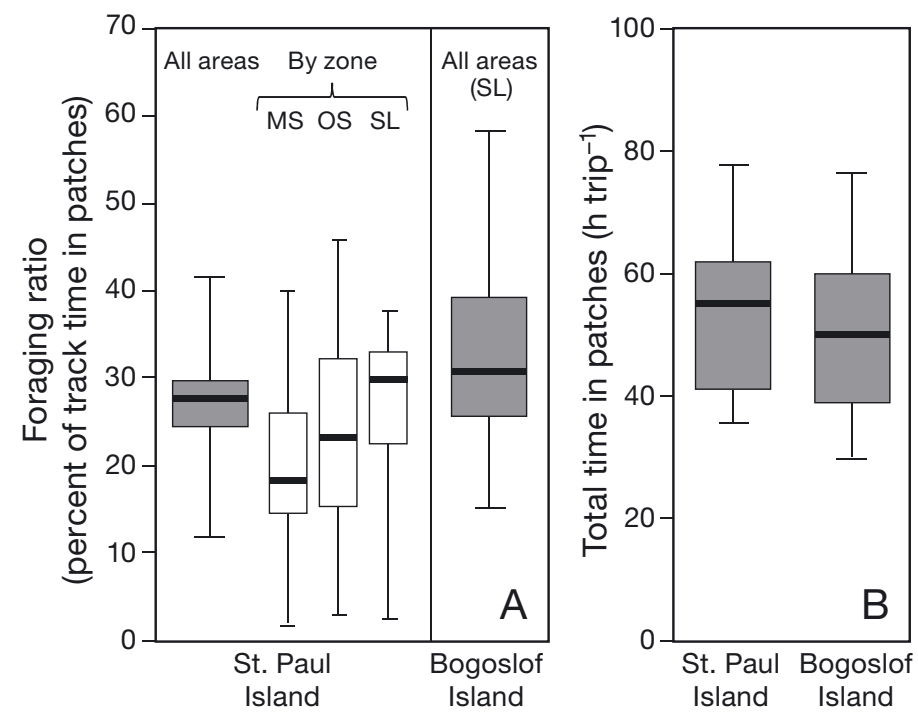

Fig. 2. Northern fur seal Callorhinus ursinus foraging effort (A) measured as a foraging ratio, defined as the percent of each track spent within patches, and (B) total time within patches for each track. Dark line: median; box: interquartile range; error bars: entire range of the data. Data from all zones around each island are shown in the gray boxes. Significant effects: island on foraging ratio (but not on total time within patches), and topographic zone on foraging ratio for St. Paul Island seals. White boxes: ratios separated by zone 
Table 1. Summary of repeated measures ANOVA for the maximum depth of each northern fur seal Callorhinus ursinus patch

\begin{tabular}{|lccc|}
\hline & $\mathrm{df}$ & $F$ & $\mathrm{p}$ \\
\hline Individual seal & 28 & 0.71 & $\mathrm{~ns}$ \\
Island & 1 & 4.90 & $<0.01$ \\
Zone & 2 & 6.67 & $<0.001$ \\
Solar angle & 43 & 11.87 & $<0.001$ \\
Day/Night/Twilight & 2 & 9.91 & $<0.001$ \\
Individual $\times$ Solar angle & 1204 & 1.98 & $\mathrm{~ns}$ \\
Individual $\times$ Day/Night/Twilight & 56 & 1.07 & $\mathrm{~ns}$ \\
Individual $\times$ Zone & 26 & 2.19 & $\mathrm{~ns}$ \\
Solar angle $\times$ Zone & 559 & 7.11 & $<0.001$ \\
Day/Night/Twilight $\times$ Zone & 4 & 9.75 & $<0.001$ \\
Individual $\times$ Solar angle $\times$ Zone & 1118 & 4.38 & $\mathrm{~ns}$ \\
Individual $\times$ Day/Night/Twilight $\times$ Zone & 52 & 2.91 & $\mathrm{~ns}$ \\
\hline
\end{tabular}

ately to the amount of time available $\left(\chi^{2}=9.68, \mathrm{df}=3\right.$, $\mathrm{p}=0.001)$. Night made up only $29 \%$ of the study period, yet $41 \%$ of Bogoslof animal patches and $39 \%$ of St. Paul animal patches occurred at night. Only $51 \%$ of patches for Bogoslof seals and $52 \%$ of patches for St. Paul seals occurred during the day, even though daytime represented $63 \%$ of the study period. This means that patches for animals from both islands made up approximately $40-45 \%$ of nighttime tracks, but only $18-25 \%$ of daytime tracks. Despite these differences in relative foraging effort between day and night, the horizontal foraging habitat used by fur seals as described by kernel densities did not vary significantly between day and night for either island (St. Paul $\chi^{2}=2.19, \mathrm{p}=0.33$; Bogoslof $\chi^{2}=$ 1.40; $\mathrm{p}=0.61$ ).

The diel variation in the depth of fur seal dives was dependent on island, zone, and time of day (measured using solar angle either binned in $2^{\circ}$ increments or binned as day/night/twilight) as summarized in Table 1 and Fig. 3. Typically, animals dove deeper at night and shallower during the day, with transitions during twilight.

The distribution of step lengths in fur seal trips was significantly different from all of the distributions representing variations in random search strategies (KS Statistics: log-logistic $=0.10$; Lévy $=0.29$, exponential $=0.81$, gamma $=0.94, \log$-normal $=0.26$, and Weibull $=0.35 ; \mathrm{p}<0.05$ for all comparisons). The loglogistic distribution fit the data best; however, there were distinct, significant mismatches between the data and this distribution, with observed values higher than the log-logistic distribution near 8, 128, and $2000 \mathrm{~m}$, and values lower than the distribution near $32 \mathrm{~m}$ and $65 \mathrm{~km}$ (Fig. 4). The log-logistic distribution was characterized by a shape parameter $(\alpha)$ of
1.31, indicative of a distribution with a broad mode, and a scale parameter $(\beta)$ of 42.48 , representing the median of the distribution.

\section{Juvenile pollock patches}

The characteristics of juvenile pollock in patches varied primarily as a function of location. The number of pollock patches on each transect, one measure of pollock distribution, varied significantly with zone $(F=8.25 ; \mathrm{df}=2,133 ; \mathrm{p}<0.001)$ but not with time of day $(F=1.201 ; \mathrm{df}=1,133 ; \mathrm{p}>0.05)$ or the interaction of zone and time $(F=1.20$; df $=2,133$; p > 0.05; ANOVA). Post-hoc analysis showed that the number of pollock patches was significantly different amongst all 3 zones with the middle shelf averaging 185 patches per transect, the outer shelf averaging 377 patches per transect, and the slope 10 patches per transect ( $\mathrm{p}<0.05$ for all comparisons).

The characteristics of individual pollock patches also varied primarily with location and with temporal effects attributable to diel vertical migration. A repeated measures MANOVA on the characteristics of aggregations of pollock showed that there were significant effects of sampling zone and time of day and a significant interaction between them, but no significant effect of transect (Table 2). The significant effects of time of day and zone were further explored for each pollock patch characteristic (summarized in Table 3). None of the pollock size or density characteristics changed with time of day. Reflecting vertical migration, the minimum, mean, and maximum depths of observed pollock patches were significantly shallower at night than during the day (minimum: $8 \mathrm{~m}$ vs. $16 \mathrm{~m}$; mean: $22 \mathrm{~m}$ vs. $39 \mathrm{~m}$; maximum: $48 \mathrm{~m}$ vs. $80 \mathrm{~m}$ ). Inter-patch horizontal spacing of pollock also changed because of diel vertical migration; inter-patch spacing in the upper $20 \mathrm{~m}$ during the day was significantly larger than the inter-patch spacing over the entire water column $(t=7.53 ; \mathrm{df}=97$; $\mathrm{p}<$ 0.001). However, the inter-patch spacing between 5 and $20 \mathrm{~m}$ at night was not significantly different from the inter-patch spacing over the upper $100 \mathrm{~m}$ at all times of day $(t=0.11 ; \mathrm{df}=97 ; \mathrm{p}=0.38)$.

Location effects were obvious when examining individual patch characteristics. Post-hoc analyses showed that pollock patches over the slope were significantly different than those over both shelf zones. Patches over the slope had, on average, more than double the density of pollock individuals (2.9 vs. 1.2 ind. $\mathrm{m}^{-3}$ ). These slope patches were also $31 \%$ smaller horizontally ( $7.1 \mathrm{~m}$ vs. $10.2 \mathrm{~m}$ ) and $37 \%$ taller 

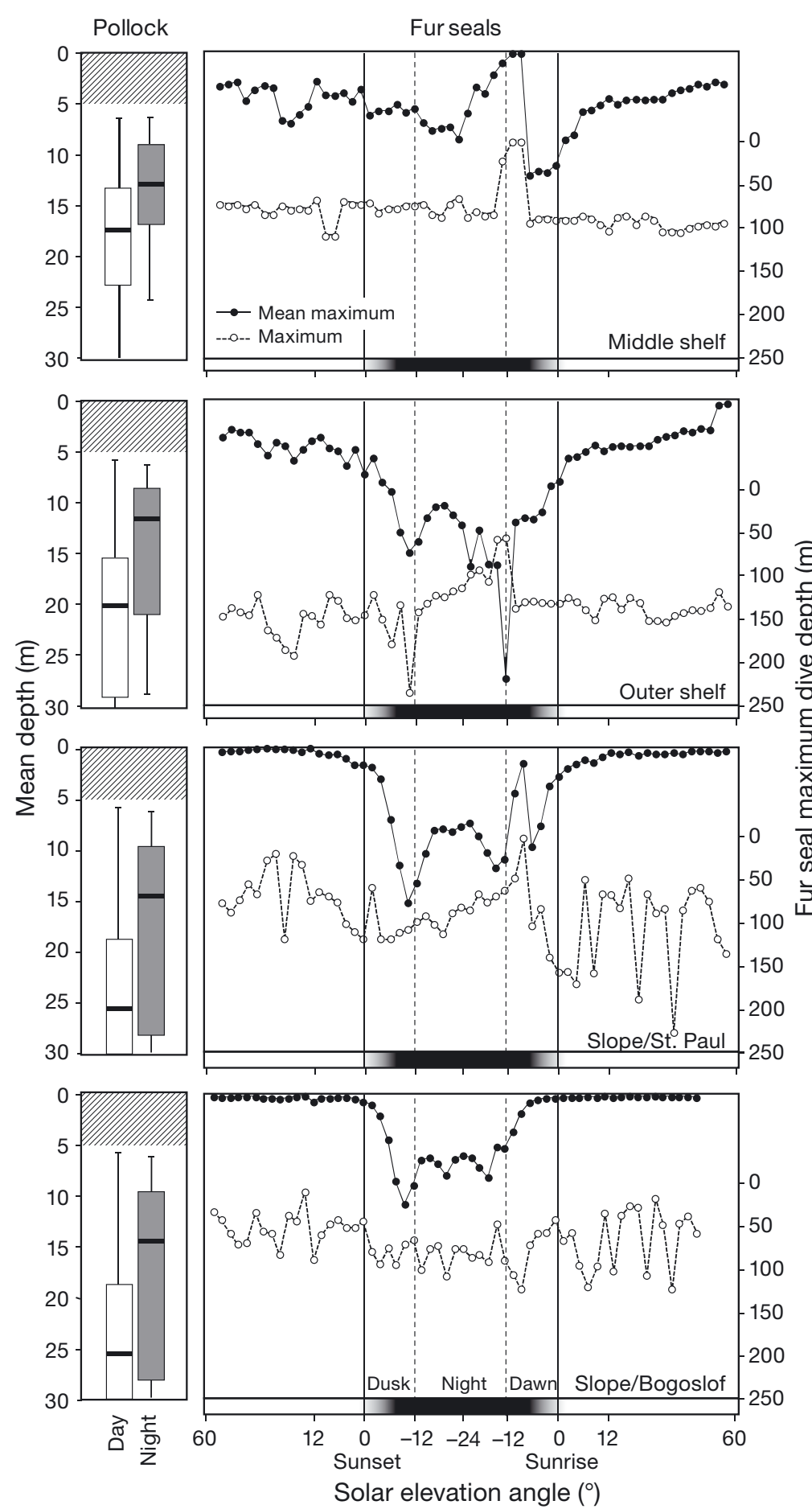

Fig. 3. Depth distribution of juvenile walleye Pollock Theragra chalcogramma and northern fur seal Callorhinus ursinus. The mean depth of pollock during day (white bars) and night (gray bars) are indicated by box plots: black line = median; box $=$ one interquartile range; error bars $=95 \%$ CI. Only the upper $30 \mathrm{~m}$ are shown so the full error bars are not always shown. Note that acoustic sampling did not cover the upper $5 \mathrm{~m}$ (hatched area). There was a significant effect of time of day and zone on pollock depth distribution (Benoit-Bird et al. 2011). On the right, the mean maximum depth of all northern fur seal patches (closed symbols and solid line) and the overall maximum of this depth (open symbols and dashed line) observed as a function of sun angle in $2^{\circ}$ increments for each topographic zone separated by rookery
$(1.2$ vs. $0.9 \mathrm{~m})$ than patches over the shelf. There were no differences in the total number of juvenile pollock within an individual patch or the total biomass of pollock in each patch between zones. There were no significant differences in pollock horizontal patch size $(F=2.63$; $\mathrm{df}=49 ; \mathrm{p}>0.05$ ) or inter-patch spacing $(F=2.17 ; \mathrm{df}=49 ; \mathrm{p}>0.05)$ in the slope zone when the data was split into 2 categories by nearest rookery. For all further scale analyses, all pollock data over the slope were combined.

\section{Horizontal scales}

Fur seals exhibited retention behavior at hierarchically nested spatial scales (Fig. 5). Fur seals were retained in small patches with an average horizontal extent of just under $10 \mathrm{~m}$ that were often further grouped together into superpatches that had an average horizontal extent of approximately $400 \mathrm{~m}$. The size of superpatches was positively correlated with the number of patches that made them up (superpatch size in $\mathrm{m}=15.57 \times$ number of patches $+91.80 ; R^{2}=0.63$ ) and the amount of time the predator spent in the aggregation (superpatch size in $\mathrm{m}=$ $42.35 \times$ time in superpatch in $\mathrm{s}-17.33$; $\mathrm{R}^{2}=0.87$ ). There were no significant effects for either rookery of distance from rookery and the size, time spent in, or number of patches in aggregations (regression analysis, $p>0.05$ ). The frequency of the observed number of patches within an aggregation including solitary patches as well as superpatches fit a power law (number of aggregations $=20041$ [number of patches in an aggregation $]^{-1.865} ; R^{2}=0.95$ ). Fig. 5 shows all of the scales of defined retention areas as well as the gaps between them. Scales of pollock aggregation were nested similarly to fur seals, though the extent of the scales that could be explicitly analyzed were limited by the length of transects $(10 \mathrm{~km})$. Results of repeated measures ANOVAs on the horizontal scales of fur seal and 


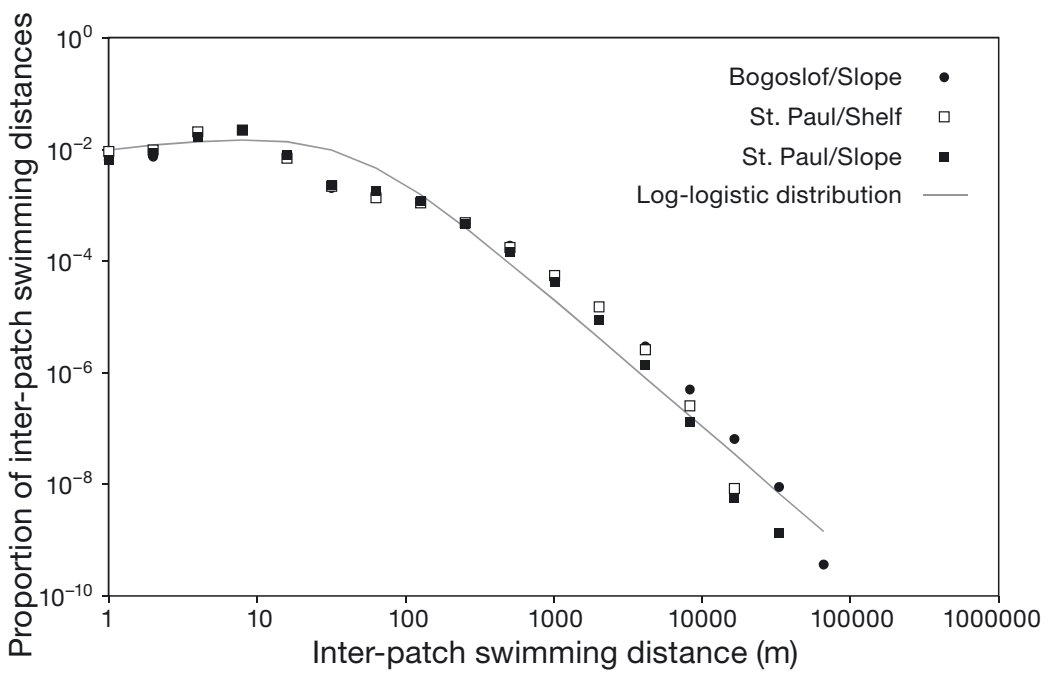

Fig. 4. Log-logistic distribution fitted to the inter-patch step distances for northern fur seals Callorhinus ursinus observed at all locations from both colonies (curve). The observed distributions of step lengths for seals tagged at 2 colonies are shown separated into patches observed on the shelf and those over the slope
$42 \%$ of daytime retention areas were made up of solitary patches. At night, $41 \%$ of onshelf retention areas were solitary patches while only $29 \%$ of offshelf retention areas were solitary patches.

Comparisons of fur seal and pollock patch and gap scales were conducted between islands split by zone when identified as statistically important (Table 4). No significant systematic differences were observed in the distributions of the horizontal extent of pollock patches and fur seal patches (Fig. 6; middle shelf $Z=-0.54, \mathrm{p}=0.59$; outer shelf $Z=-0.74, \mathrm{p}=0.38$; St. Paul slope seals $Z=-1.51, \mathrm{p}=0.13$; Bogoslof seals $Z=-1.10, \mathrm{p}=0.27)$. There were no significant differences observed between onshelf seal inter-patch distances and
Table 2. Summary of a multivariate repeated measures ANOVA for juvenile walleye pollock Theragra chalcogramma patch characteristics

\begin{tabular}{|lccc|}
\hline Effect & df & $F$ & $\mathrm{p}$ \\
\hline Transect & 97 & 0.61 & $\mathrm{~ns}$ \\
Zone & 2 & 4.63 & $<0.001$ \\
Day/Night & 1 & 3.54 & $<0.001$ \\
Zone $\times$ Day/Night & 2 & 2.51 & $<0.001$ \\
\hline
\end{tabular}

pollock patch and gap sizes are summarized in Table 4.

While the sizes of seal individual patches and the size of superpatches did not change with time of day (Table 4), the number of patches making up the largest observed scale of fur seal retention areas (either solitary patch or superpatch) was affected by zone $(F=4.49$, df $=2$, p < $0.01)$, time of day $(F=6.29, \mathrm{df}=1, \mathrm{p}<0.005)$, and their interaction $(F=18.93$, df $=2, \mathrm{p}<0.001)$. Onshelf, the average retention area consisted of about 6 patches while offshelf, the average retention area was made up of nearly 12 patches. During the day, the average fur seal retention area consisted of 4 patches while at night, it was made up of more than 16 patches. Examining whether or not the largest retention areas were either single patches or superpatches shows similar patterns $\left(\chi^{2}=13091.5\right.$, df $=3$, p < 0.001). Onshelf, $66 \%$ of retention areas during the day were solitary patches while offshelf,
Table 3. Summary of MANOVA effects for each juvenile walleye pollock Theragra chalcogramma patch characteristic

\begin{tabular}{|c|c|c|c|c|}
\hline Effect & Variable & df & $F$ & $\mathrm{p}$ \\
\hline \multirow[t]{11}{*}{ Zone } & Patch mean depth & 2 & 2.29 & ns \\
\hline & Patch max depth & 2 & 3.38 & $<0.05$ \\
\hline & Patch min depth & 2 & 7.61 & $<0.001$ \\
\hline & Patch horizontal length & 2 & 3.87 & $<0.05$ \\
\hline & Patch thickness & 2 & 4.44 & $<0.01$ \\
\hline & Patch area & 2 & 2.22 & $\mathrm{~ns}$ \\
\hline & Nearest patch distance & 2 & 10.02 & $<0.001$ \\
\hline & Patch mean density & 2 & 11.05 & $<0.001$ \\
\hline & Patch max density & 2 & 8.95 & $<0.001$ \\
\hline & Patch total biomass & 2 & 1.83 & ns \\
\hline & Total number of fish in patch & 2 & 2.06 & ns \\
\hline \multirow[t]{11}{*}{ Day/Night } & Patch mean depth & 1 & 14.57 & $<0.001$ \\
\hline & Patch max depth & 1 & 14.02 & $<0.001$ \\
\hline & Patch min depth & 1 & 12.16 & $<0.001$ \\
\hline & Patch horizontal length & 1 & 0.09 & ns \\
\hline & Patch thickness & 1 & 0.97 & ns \\
\hline & Patch area & 1 & 2.56 & $\mathrm{~ns}$ \\
\hline & Nearest patch distance & 1 & 0.02 & ns \\
\hline & Patch mean density & 1 & 0.19 & ns \\
\hline & Patch max density & 1 & 0.72 & $\mathrm{~ns}$ \\
\hline & Patch total biomass & 1 & 0.11 & ns \\
\hline & Total number of fish in patch & 1 & 0.06 & ns \\
\hline \multirow{11}{*}{$\begin{array}{l}\text { Zone } \times \\
\text { Day/Night }\end{array}$} & Patch mean depth & 2 & 5.85 & $<0.001$ \\
\hline & Patch max depth & 2 & 6.44 & $<0.001$ \\
\hline & Patch min depth & 2 & 1.20 & $\mathrm{~ns}$ \\
\hline & Patch horizontal length & 2 & 1.87 & ns \\
\hline & Patch thickness & 2 & 2.96 & ns \\
\hline & Patch area & 2 & 1.46 & ns \\
\hline & Nearest patch distance & 2 & 2.25 & ns \\
\hline & Patch mean density & 2 & 0.81 & ns \\
\hline & Patch max density & 2 & 1.16 & ns \\
\hline & Patch total biomass & 2 & 2.18 & ns \\
\hline & Total number of fish in patch & 2 & 0.92 & ns \\
\hline
\end{tabular}




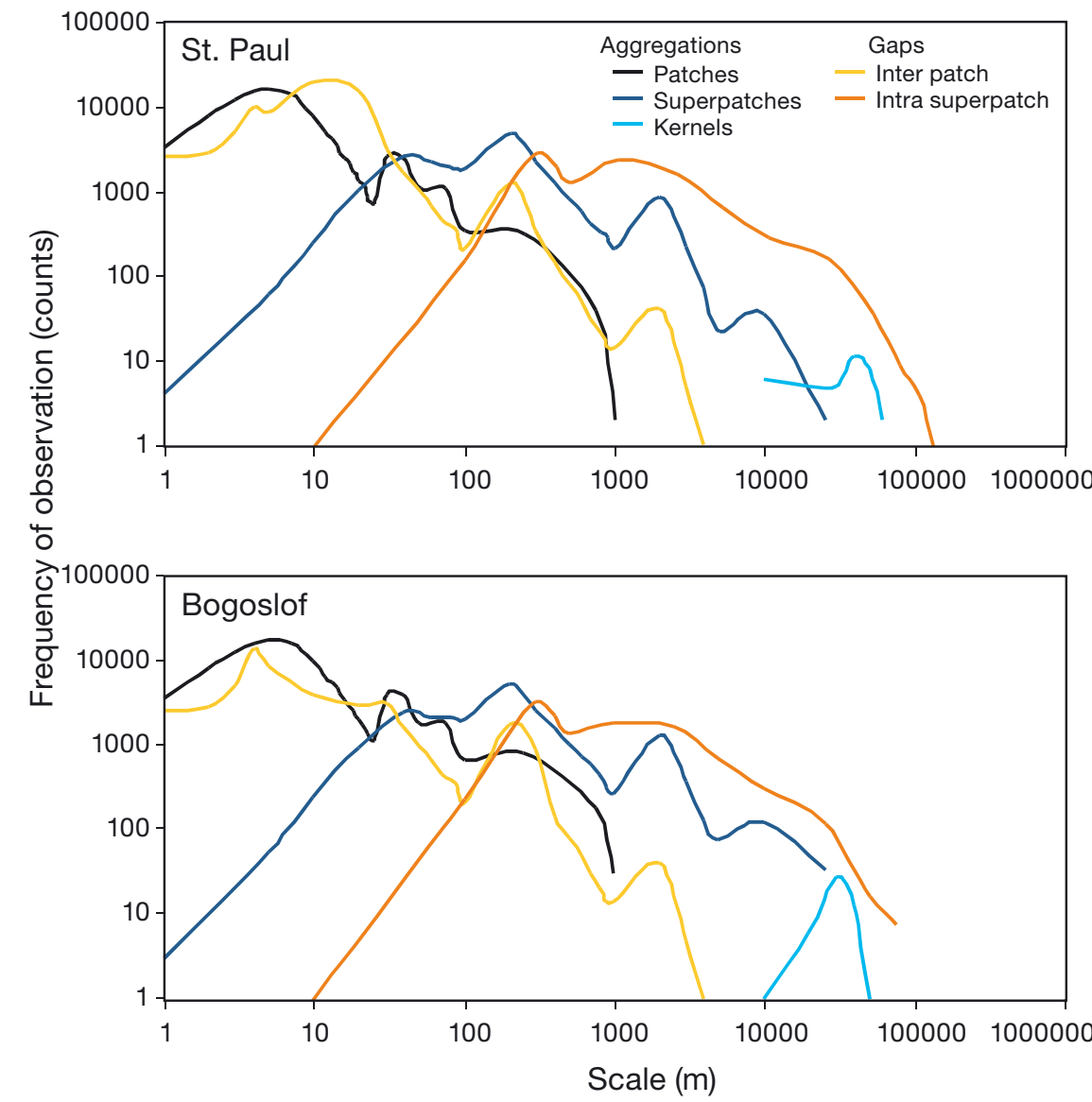

Fig. 5. Spatial scales observed in areas of northern fur seal Callorhinus ursinus retention, or aggregations, shown in cool colors and spaces between retention areas, or gaps, shown in warm colors pollock inter-patch distances at the same locations (Fig. 7; middle shelf $Z=-0.19, \mathrm{p}=0.88$; outer shelf $Z=$ 0.08, p = 0.95). However, both Bogoslof seals and St. Paul seals over the slope had significantly smaller interpatch distances than pollock (St. Paul seals: $Z=-2.81, \mathrm{p}<0.001$; Bogoslof seals $Z=-1.62$, $\mathrm{p}<0.001)$. No significant differences were observed in the distributions of the horizontal extent of pollock superpatches and fur seal superpatches (Fig. 8; middle shelf $Z=-0.18, \mathrm{p}=0.86$; outer shelf $Z=-0.33, \mathrm{p}=0.74$; St. Paul slope seals $Z=-0.08, \mathrm{p}=0.94$; Bogoslof seals $Z=-0.09, \mathrm{p}=0.93$ ). No significant effect of zone was observed on either fur seal or pollock inter-superpatch distances, but fur seal intersuperpatch distances were affected by island (Table 4). Therefore, data were pooled by island for comparison of inter-superpatch distances which showed that there was no difference between St. Paul seals and pollock (Fig. 9; $Z=-0.76, \mathrm{p}=0.54$ ). However, Bogoslof seal inter-superpatch distances were significantly smaller than those of pollock $(Z=$ $-1.99, \mathrm{p}<0.01)$.

Table 4. Summary of repeated measures ANOVAs on the horizontal size of aggregations and gaps for both northern fur seals Callorhinus ursinus and juvenile walleye pollock Theragra chalcogramma. Bold: significant; ns: not significant

\begin{tabular}{|c|c|c|c|c|c|c|c|c|c|c|c|}
\hline & \multirow[t]{3}{*}{$\mathrm{df}$} & \multicolumn{2}{|c|}{ Patches } & \multirow{2}{*}{\multicolumn{2}{|c|}{$\begin{array}{l}\text { Interpatch } \\
\text { spacing }\end{array}$}} & \multicolumn{2}{|c|}{ Superpatches } & \multirow{2}{*}{\multicolumn{2}{|c|}{$\begin{array}{l}\text { Superpatch } \\
\text { spacing }\end{array}$}} & \multicolumn{2}{|c|}{ Kernel } \\
\hline & & \multirow[t]{2}{*}{$F$} & \multirow{2}{*}{$\mathrm{p}$} & & & \multirow[t]{2}{*}{$F$} & \multirow[t]{2}{*}{$\mathrm{p}$} & & & \multirow[t]{2}{*}{$F$} & \multirow[t]{2}{*}{$\mathrm{p}$} \\
\hline & & & & $F$ & $\mathrm{p}$ & & & $F$ & $\mathrm{p}$ & & \\
\hline \multicolumn{12}{|l|}{ Fur seals } \\
\hline Individual seal & 28 & 1.45 & ns & 0.96 & ns & 1.79 & ns & 0.93 & ns & 1.11 & ns \\
\hline Island & 1 & 0.74 & ns & 1.35 & ns & 7.84 & $<0.001$ & 4.10 & $<0.001$ & 9.79 & $<0.002$ \\
\hline Day/Night & 2 & 0.82 & ns & 0.56 & ns & 2.85 & ns & 1.07 & ns & 1.67 & - \\
\hline Zone & 2 & 6.67 & $<0.001$ & 29.13 & $<0.001$ & 9.89 & $<0.001$ & 0.86 & ns & 1.05 & - \\
\hline Individual $\times$ Day/Night & 56 & 1.22 & $\mathrm{~ns}$ & 1.07 & ns & 5.61 & $<0.005$ & 0.95 & ns & 0.55 & - \\
\hline Individual $\times$ Zone & 26 & 4.06 & $<0.001$ & 37.95 & $<0.001$ & 3.59 & 0.02 & 0.83 & ns & 0.81 & - \\
\hline Day/Night $\times$ Zone & 4 & 0.84 & ns & 1.46 & ns & 0.56 & ns & 1.16 & ns & 1.16 & - \\
\hline Individual $\times$ Day/Night $\times$ Zone & 52 & 4.01 & $<0.001$ & 1.69 & ns & 0.72 & ns & 0.28 & ns & 0.28 & - \\
\hline \multicolumn{12}{|l|}{ Pollock } \\
\hline Transect & 97 & 0.18 & ns & 0.87 & ns & 1.10 & ns & 0.11 & ns & - & - \\
\hline Day/Night & 1 & 1.57 & ns & 1.29 & ns & 0.72 & ns & 0.96 & ns & - & - \\
\hline Zone & 2 & 7.19 & $<0.001$ & 5.62 & $<0.001$ & 3.90 & $<0.02$ & 1.42 & ns & - & - \\
\hline Day/Night $\times$ Zone & 4 & 1.82 & ns & 1.25 & $\mathrm{~ns}$ & 0.94 & $\mathrm{~ns}$ & 1.03 & ns & - & - \\
\hline
\end{tabular}




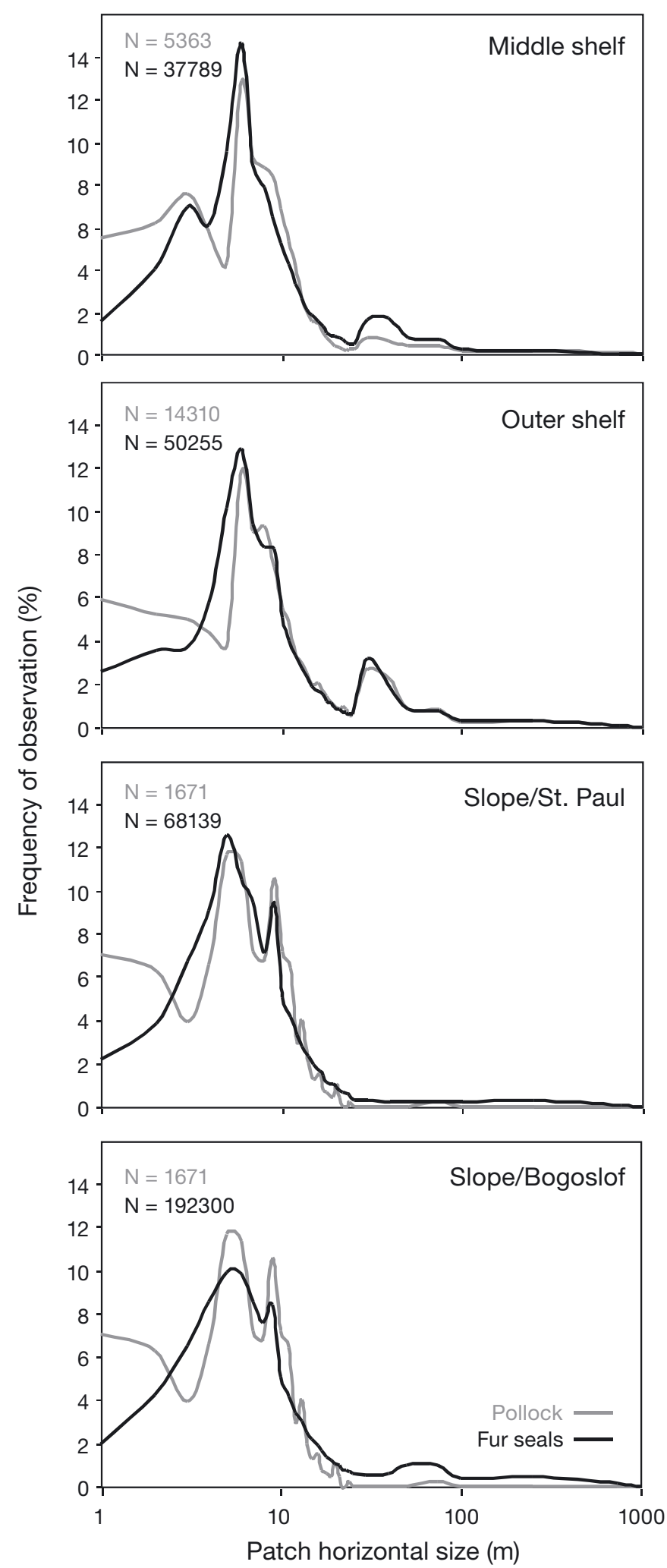

Fig. 6. Frequency distribution of juvenile walleye pollock Theragra chalcogramma (gray) and fur seal Callorhinus ursinus (black) patches. St. Paul Island fur seal patches and all pollock patches are broken up by topographic zone
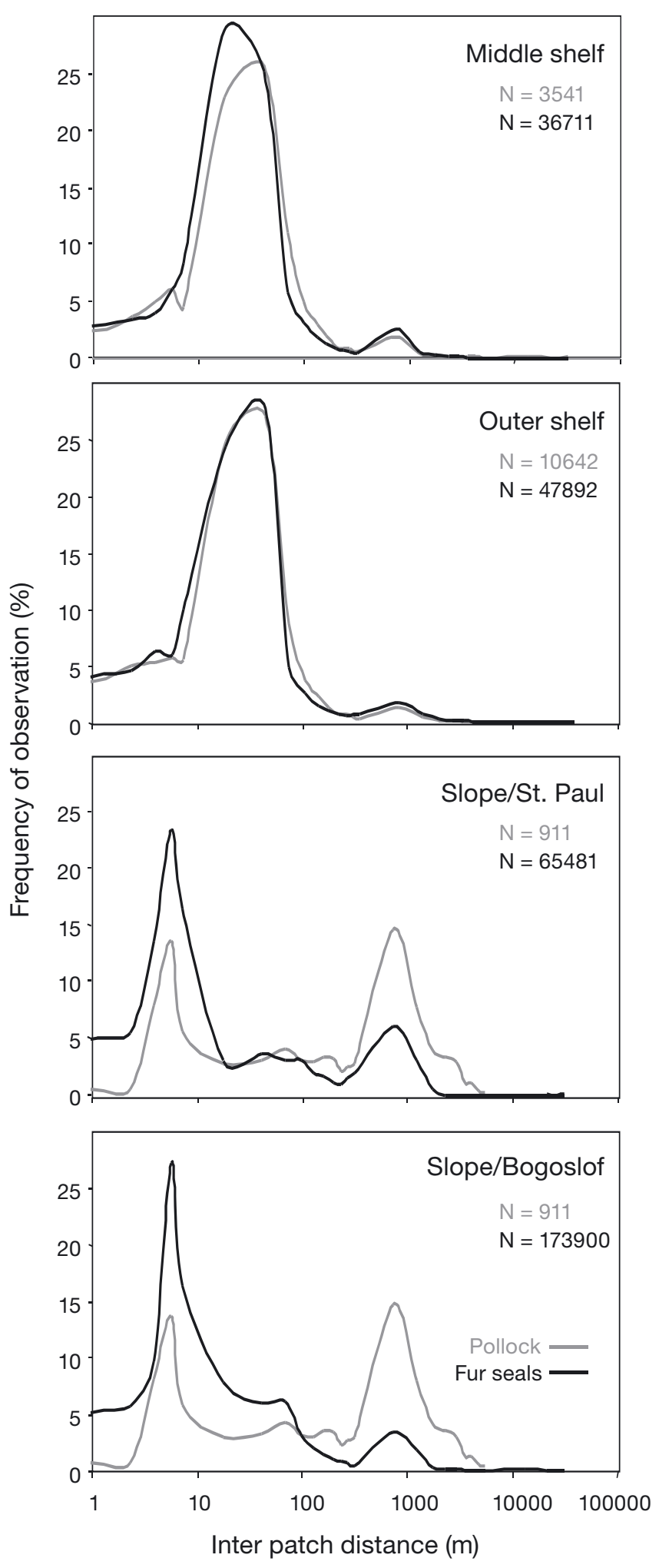

Fig. 7. Frequency distribution of nearest neighbor distances for juvenile walleye pollock Theragra chalcogramma (gray) and northern fur seal Callorhinus ursinus (black) patches. St. Paul Island fur seal inter-patch distances and all pollock inter-patch distances are broken up by topographic zone 


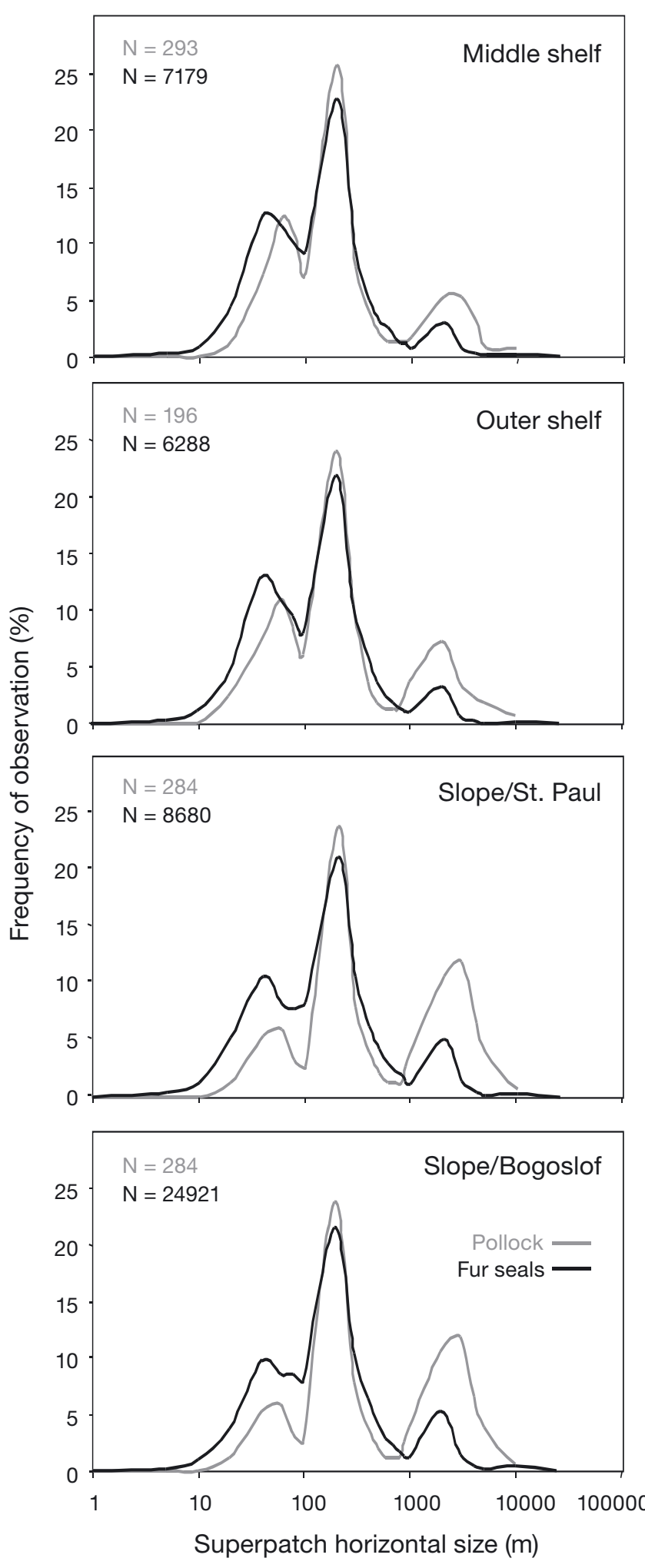

Fig. 8. Frequency distribution of juvenile walleye pollock Theragra chalcogramma (gray) and northern fur seal Callorhinus ursinus (black) superpatches. St. Paul Island fur seal superpatches and all pollock superpatches are broken up by topographic zone

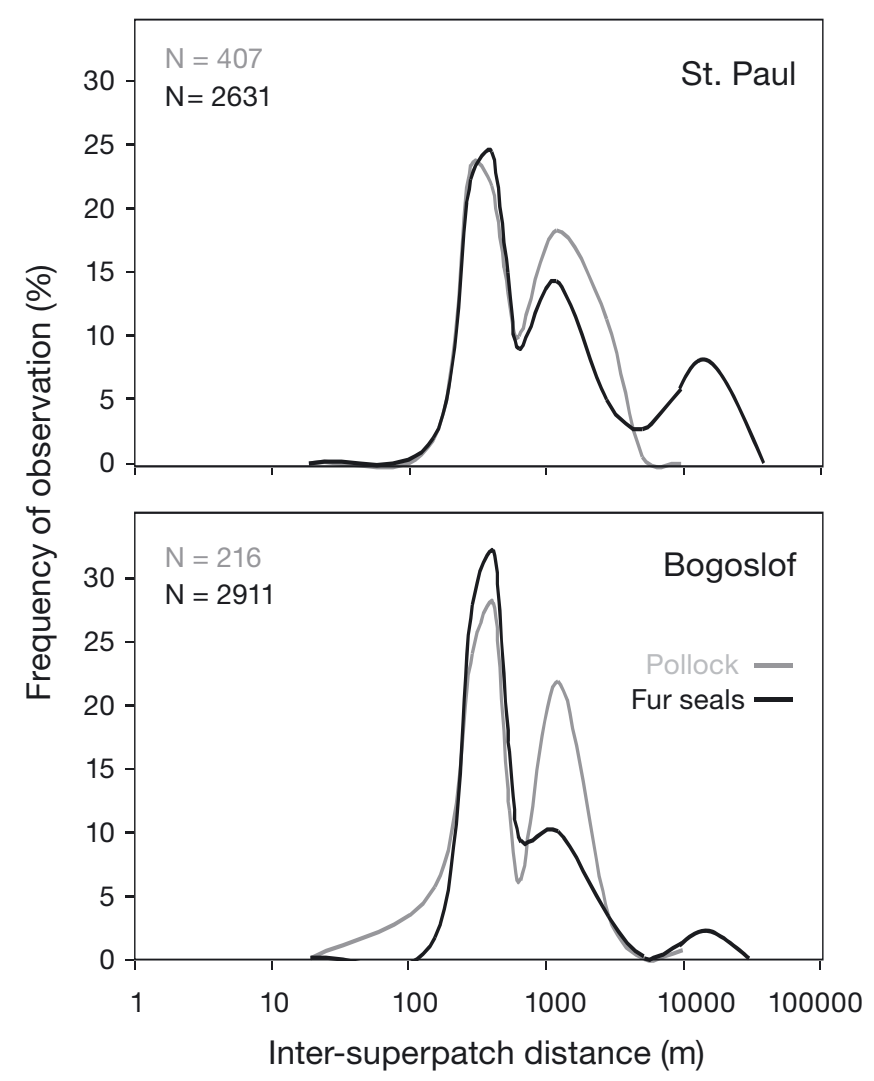

Fig. 9. Frequency distribution of nearest neighbor distances for juvenile walleye pollock Theragra chalcogramma (gray) and northern fur seal Callorhinus ursinus (black) superpatches smaller than $10 \mathrm{~km}$, the length of a single transect. There was no significant effect of zone on inter-superpatch distance over this scale, so data are shown by island. Note that because of the sampling design, values for pollock above a few kilometers should be interpreted carefully

\section{DISCUSSION}

\section{Search strategy}

The search strategies of fur seals tagged at 2 breeding islands in the Bering Sea showed that they do not use a random search pattern. Instead, their searches showed characteristic spatial scales. The step lengths between areas of retention did not fit distributions hypothesized for random walks (Fig. 4), but instead showed distinctive peaks at scales of 8 , 128 , and $2000 \mathrm{~m}$ and nulls near $32 \mathrm{~m}$ and $65 \mathrm{~km}$. It is important to note that if only scales $>100 \mathrm{~m}$ were included in the analysis, it would have been possible - using an approach from previous studies (e.g. Sims et al. 2008), but contested by Edwards et al. (2007) to have identified a Levy walk pattern with the fractal dimension of the distribution $(\mu)$, of 2.4 , consistent 
with a highly efficient search pattern. While robust statistical evaluation does not support a Levy pattern even at these larger scales, deviations from a distribution predicted by a random walk were visually identifiable at scales smaller than $100 \mathrm{~m}$. These small scale behaviors would not have been resolved using only surface locations (i.e. GPS used in this study with $\sim 50$ to $100 \mathrm{~m}$ horizontal resolution; Hazel 2009), highlighting the importance of using appropriately resolved data in the analysis of foraging behavior (Edwards et al. 2007).

The non-random patterns of fur seal step lengths reflect the scales of retention areas, or patches, identified in fur seal behavior within this system. These areas of retention and the gaps between them were hierarchically nested, with horizontally small patches clustered together into larger aggregations we termed 'superpatches', which were clustered into even larger areas identified using kernel statistics. The spaces between areas of retention within a scale were similar to, or slightly larger than, the areas themselves (Fig. 5). The presence of this hierarchical structure in fur seal movement masks patterns present in their movement when examining movement without differentiating its type. The advantages of identifying the nested nature of both positive areas (patches) and the connections between them when assessing the mechanisms of animal foraging is highlighted by comparing Fig. 4 (the sum of all movements) with Fig. 5 (those same movements split by whether they help an animal remain within an area of interest or move an animal to the next area with careful assignment of variance in behavior to levels in a hierarchy; Fauchald et al. 2000).

As with fur seals, juvenile walleye pollock in the study area occurred in aggregations at hierarchically nested spatial scales. Small patches $<10 \mathrm{~m}$ in horizontal extent were clustered with other juvenile pollock patches to form 'superpatches'. Larger scales of pollock aggregation are likely (Ressler et al. 2012) but could not be identified with the methods used here. Juvenile pollock patches had a median depth of $22 \mathrm{~m}$ during the day and $14 \mathrm{~m}$ at night. Even with vertical movement, the horizontal scales of these young pollock remained consistent throughout the day and night.

Throughout day and night, patches in fur seal tracks occurred primarily in the upper water column, at depths $<15 \mathrm{~m}$. The absolute maximum depth observed within fur seal patches in the middle shelf occurred near the seafloor depth of $100 \mathrm{~m}$. Similarly, in some areas of the outer shelf, the maximum depths reached the seafloor. However, $<5 \%$ of patches had maximum depths $>30 \mathrm{~m}$. This was true at all times and locations - hence, fur seals only rarely formed patches near the seafloor. This does not mean that fur seals were not foraging on the seafloor given that some fur seals over the shelf spent considerable time foraging at or near the bottom (Nordstrom et al. 2013). However, seals using these areas largely moved in straight lines (Kuhn et al. 2010) which prevented identification of these foraging events by the methods we used. Like pollock patches, the horizontal scales of fur seal patches were not affected by time of day, even though fur seals spent about twice as much time in patches at night than during the day; consistent with the relative day and night activity levels reported previously (Ichihara \& Yoshido 1972).

\section{Predator-prey coherence}

The consistency of horizontal patch scales for both juvenile pollock and lactating fur seals across the diel cycle allowed us to compare the distributions of these scales despite differences in sampling effort. We found that the distribution of the scales of patches of both pollock and fur seals were very similar across all spatial scales we were able to compare (e.g. up to the length of our survey transects, $10 \mathrm{~km}$; Figs. 6 to 9). Most striking was that the differences observed in the spatial scales of pollock between the shelf and slope areas corresponded with the difference in fur seal patches between the 2 habitats. This indicates that search strategies of fur seals are not innate patterns decoupled from the environment. Instead, aggregations of juvenile pollock appear to form the spatial backbone of the strategy that fur seals use to move through the habitat while foraging. This was true for seals from both rookeries even though juvenile pollock made up very little of the fur seal diet on Bogoslof Island (Zeppelin \& Orr 2010, A. W. Trites unpubl. data).

The fact that fur seal patches match the scale of individual patches of pollock, even when pollock are only a limited portion of their diet as on Bogoslof Island, is likely a result of our attention to areas of spatial retention in fur seal movement. Schooling prey such as pollock and other species (i.e. Atka mackerel, sandlance, stickleback, and herring) that contribute to the diet of Bogoslof fur seals may be more likely to result in this retention than solitary or loosely aggregated prey such as the mesopelagic squid and fish that make up the largest portion of the diet of seals from Bogoslof Island. As with other researchers, we observed these mesopelagic prey distributed in ex- 
tensive, low density layers (Pearcy et al. 1979, Sinclair $\&$ Stabeno 2002) rather than the small schools of polarized, densely packed individuals observed in juvenile pollock and other fur seal prey species.

The congruence in the gaps between patches and superpatches in fur seal movements and juvenile pollock suggests that predictable aggregations of schooling species serve as bases defining the spatial pattern which connects the remainder of their foraging efforts. Using patches of predictable prey such as juvenile pollock as bases in their swimming path would present a viable strategy that fur seals could use to search for all prey species, relying on the relative guarantee of finding prey schools through patterned movement even while exploiting more randomly or evenly distributed prey of higher quality such as mesopelagics when they are encountered along this path. Predator search efficiencies are predicted to be greater in hierarchically nested prey systems (Fauchald 2009), as we observed for juvenile pollock, in contrast to the largely unstructured systems observed in mesopelagic prey species at this spatial scale.

\section{Fur seals preferences}

Fur seals formed patches with sizes roughly in proportion to those of juvenile pollock within oceanographically distinct zones (Coachman 1986), regions previously shown to define fur seal foraging areas (Goebel et al. 1991, Robson et al. 2004, Zeppelin \& Ream 2006). However, over the deep waters of the slope zone, the spacing between fur seal patches was biased towards the lower mode of inter-patch distances of pollock ( 8 m, Fig. 7). In all zones, fur seals occurred in higher proportions in small $(\sim 70 \mathrm{~m})$ superpatches than pollock, and in lower proportions in large ( 2500 m) superpatches than pollock (Fig. 8). Fur seals also tended to have shorter inter superpatch distances than the overall distribution of these measurements in pollock (Fig. 9). So, while the spatial behavior of fur seals closely matched the spatial distribution of juvenile pollock, fur seals did not use the pollock aggregations randomly.

\section{Population differences}

Considering the entire habitat available for foraging, fur seals from the 2 rookeries we studied showed a clear preference for waters $\geq 200 \mathrm{~m}$ deep. Fur seal foraging behavior was concentrated over the slope where juvenile pollock patches were denser, rather than the shelf where pollock patches were more abundant and larger. Selecting deep water habitats resulted in St. Paul fur seals ranging much further from the rookery than those tagged on Bogoslof Island. The trips from St. Paul were nearly double the duration of those from Bogoslof, perhaps influenced by higher competition near the larger rookery.

Bogoslof rookery seals spent significantly more of their trip time forming patches than seals from St. Paul (Fig. 2). St. Paul seals spent a lower proportion of time feeding, in part due to having greater transit times to and from the slope from the shelf — although restricting the comparison to only time spent off the slope still showed that St. Paul seals spent less time in patches than those from Bogoslof Island. Whether this difference reflects differences in intraspecific competition or differences in the availability of alternate prey species is unknown; however, it might play a role in explaining the population growth at Bogoslof Island and the fur seal decline at St. Paul Island.

Both populations of fur seals spent the same total time per trip within patches (Fig. 2), in contrast to the predictions generated from central place foraging theory which suggest that time in patches should increase as distance from the colony increases (Orians \& Pearson 1979). The constant total patch time we measured may indicate the time that seals need to spend foraging within patches to optimize the benefit of a foraging trip, regardless of the amount of foraging that occurs outside of patches (which, based on diet, is quite different between these colonies). Data from additional years with different prey conditions would be valuable in testing this hypothesis.

\section{Temporal patterns}

In addition to the spatial scales that we observed in fur seal foraging behavior, patterns emerged from our analysis at 2 temporal scales. First, fur seals foraging in waters $\geq 200 \mathrm{~m}$ deep underwent diel vertical migrations, meeting their prey as it ascended towards the surface near dusk as observed in previous studies (Kuhn et al. 2010). Fur seals followed their prey towards the surface throughout the night, before they followed it deeper as dawn approached, forming a ' $\mathrm{W}$ ' in dive depths over the course of a night. These vertical movements averaged 10-15 m each night, similar to the diel vertical movement observed in juvenile pollock which averaged a depth change between 8 and $17 \mathrm{~m}$. The maximum dive depths of fur seals over the slope overlapped nearly 
perfectly with that of juvenile pollock in the same area at night. The vertical movement of seals was, however, asymmetrical, with a greater descent at dusk than at dawn; a pattern observed in predators of a range of sizes following vertically migrating prey (Benoit-Bird \& Au 2003, 2006), but one that has not been previously described in northern fur seals. The asymmetrical diel migration in fur seals is likely due to a decreased benefit/cost ratio of foraging at depth at dawn relative to dusk because of satiation, detection limitations, or asynchrony in the migration of their prey (Enright 1977, De Robertis 2002). Unfortunately, the temporal resolution of our prey data does not allow us to separate these hypotheses.

A second temporal pattern in patch formation was observed within individual fur seal trips. Fur seals from St. Paul Island that did not spend considerable time in the middle shelf formed patches in their swimming paths in shallow waters on the outbound component of each trip. However, they did not form them on the way back to the rookery. Again, this asymmetry points to a change in the benefit/cost ratio - most likely a combination of attaining enough resources for the trip and the need to return to feed their pups. This pattern would have been missed entirely if we had employed the approach to categorizing foraging from previous work (Gentry et al. 1986) and excluded all behavior $\leq 5 \mathrm{~m}$ from the surface, as all patches formed by fur seals over the shelf on their trips out to deep water occurred near the surface.

In contrast to previous efforts (Gentry et al. 1986, Gentry et al. 1998), our data indicate that fur seals forage at all times of the day and night. Using patterns in tortuosity to define patches in a predator has an advantage over traditional methods because it utilizes the animal's behavior to identify regions of retention during active swimming, but requires few other assumptions about what foraging should look like. Using depth (Gentry et al. 1986) or depth pattern (Gentry et al. 1998) to identify feeding has resulted in the exclusion of all daytime surface behavior in previous descriptions of fur seal foraging. The majority of dives we recorded over the slope were $>5 \mathrm{~m}$ and occurred at night. As a result, during dark periods, our approach resulted in similar classifications of foraging areas to those employing only depth as a criteria. However, our results showed that daytime patches did not differ from nighttime patches (other than their depths) although areas of retention occurred about half as often during the day compared to night. The fact that patches formed by fur seals have the same horizontal scales during day and night indicates a common set of drivers or selective mechanisms. These foraging locations should not be excluded from descriptions of fur seal foraging efforts.

Similar to the patterns observed in fur seal patches, the horizontal scales of juvenile pollock patches did not differ with time of day. At all times, pollock patches near the surface $(5-20 \mathrm{~m})$ were the same scale as those found at depth $(20-100 \mathrm{~m})$. This indicates that the primary driver for the formation of fur seal patches was indeed pollock throughout the diel cycle. The decreased frequency with which seals displayed patch formation during the day likely reflects the decreased number of pollock patches found in surface waters during the day. Our data suggest that fur seals forage for juvenile pollock throughout the entire diel cycle. Diving to deeper depths at night would allow fur seals to access more of these pollock patches as they rise towards the surface and become denser in surface waters while simultaneously facilitating foraging on the other diel migrators (myctophid fish, squid, and northern smoothtongue) that make up their diet.

\section{Analysis of the approach}

A second advantage to the technique we used to identify fur seal foraging is that it does not define the spatial scale of patches a priori as in many other methods (reviewed in Horne \& Schneider 1995), allowing a wide range of patch sizes to be detected. The minimum size of a detectible patch is based on the swimming speed of the animal as well as on how much turning the animal does. In practice, our minimum consistently observed patches were approximately $1 \mathrm{~m}$, approaching the length of an individual seal.

Analyzing the spatial patterns as we did was critical to identifying the nested scales of fur seal foraging patterns. Non-stationarity is a key property of hierarchical patch systems (e.g. the probability of a spatial process is unequal throughout space). Thus, the results from global analyses of spatial structure (variograms, correlograms, spectral analyses, wavelets, and fractals) are highly confounded (Fauchald et al. 2000) such that large-scale patterns mask nested small-scale patterns.

One concern about using high-resolution, modeled animal movement is the errors inherent in the absolute positions between known locations. However, even when track reconstruction results in errors such that true positions cannot be resolved, the relative movement displayed by the animal can still be usefully assessed in a behavior context provided the 
time interval over which the analysis is conducted is not excessive (Wilson et al. 2007). In this case, fur seal aggregations larger than individual patches were at spatial scales greater than distances between the GPS positions that anchored the tracks, limiting the importance of reconstruction errors at these large scales, while individual patches occurred at temporal scales of $\sim 1 \mathrm{~min}$, limiting the potential for significant errors in relative position. Our estimates of the track compression and expansion necessary to match GPS positions indicate that the errors are unbiased, meaning that the mean patch sizes are unlikely to be affected by track estimation errors. Instead, errors would affect the spread of the distribution. The standard deviation in the distribution of estimated track expansion and compression provides an estimate of the potential change in dispersion due to track reconstruction errors; $25 \%$ for both islands.

Evidence that reconstructed tracks are useful in assessing the multi-scale tortuosity of complete animal tracks without bias for scale (Wilson et al. 2007) is found by comparing fur seal scale patterns between islands. While there are no differences observed in patch and inter-patch size distributions for slope animals from the 2 colonies, as might be expected due to differences in GPS location updates, there were clear differences between habitat types for St. Paul animals (Figs. 6 \& 7, for example). Variation in the behavior of animals from these 2 populations was greater than the errors in estimating the scale of these behaviors through track reconstruction.

\section{Hierarchical foraging}

Examining patterns in the tortuosity of high-resolution reconstructed animal tracks shows that fur seals are able to perceive and respond to prey variability at scales ranging from $<10 \mathrm{~m}$ through the $10 \mathrm{~km}$ scale of our transects. Given that we were unable to find a spatial scale in prey that fur seals did not match or selectively avoid, we may not have sampled prey finely enough to determine the smallest scale (the grain of heterogeneity; Kotliar \& Wiens 1990) that fur seals can perceive and respond to. It is possible for a fur seal to respond to heterogeneity in the distribution or quality of prey at the level of the individual, the smallest scale at which it is possible to define grain for a species that consumes prey whole. This is remarkably fine sampling for a predator foraging over such a wide area of the ocean. Testing this hypothesis in the field, however, presents incredible sampling challenges.
Fur seals also showed spatial pattern in their foraging at scales larger than the $10 \mathrm{~km}$ scale of prey sampling, with a clustering in their behavior at a scale of 30 to $50 \mathrm{~km}$. Thus, we are unable to define the largest scale of prey (the extent; Kotliar \& Wiens 1990) that they respond to - the upper limit of which is likely set by an individual's need to return to her offspring rather than the distribution of prey. However, given the tight coupling in spatial scales between pollock and fur seals at the scales where we have measurements for both, it is reasonable to suggest that juvenile pollock are also aggregated at 30 to $50 \mathrm{~km}$.

The 'habitat' of the Bering Sea as defined by female fur seals rearing pups encompasses a wide range of scales from $<1 \mathrm{~m}$ to $>50 \mathrm{~km}$. This understanding provides critical information on the perception of space by these animals and identifies the scales that must be considered when assessing processes driving individual behaviors and population dynamics (Johnson et al. 2002). Our preliminary descriptions of the smallest and largest scales of patch response of fur seals provide reference scales that facilitate comparison to the structure of spatial heterogeneity in other predator-prey systems (Kotliar \& Wiens 1990). While studies of hierarchical patchiness remain limited in marine systems, we found that fur seals have a substantially finer grain than the other pelagic marine predators for which this has been defined (Fauchald et al. 2000, Fritz et al. 2003), perhaps because of the relative consistency of pollock patch characteristics compared to the rapidly evolving prey patches in these studies.

Our analytic approach permitted measurements of predators at broader extents than these other studies as well (but see Fauchald \& Tveraa 2006, Weimerskirch et al. 2007), yet did not define the upper limit of fur seal extent in relation to prey. Once the limits of fur seal patch response can be fully defined, these standardized metrics of spatial heterogeneity will permit comparisons to studies in terrestrial systems where hierarchical patch studies are becoming common, particularly in the context of landscape ecology (Wiens 1989, Zhang \& Sanderson 1993, Girvetz \& Greco 2007). Further refining the scale of the fur seal foraging response can also inform modeling efforts that have begun to tackle foraging in these complex, realistic prey regimes (Fauchald 1999, Nams 2005).

In addition to demonstrating that fur seals respond to prey over a wide range of scales, we showed that fur seals are able to simultaneously respond to several levels of prey patchiness. This resulted not only in strong correlations between predator and prey at one scale, but over the entire range of aggregation 
scales observed in juvenile pollock. This differs from other examinations of hierarchical predator-prey interactions (Fauchald et al. 2000, Fauchald 2009) and scale-dependent analyses (Schneider \& Piatt 1986, Logerwell et al. 1998, Mehlum et al. 1999) in pelagic marine systems where coherence has been observed over only part of the range of observed scales. The presence of this sort of hierarchical, scale-dependent aggregation influences to what degree we can understand predator behavior and predict predator-prey interaction dynamics (Wu \& Loucks 1995).

Hierarchical patch structure may explain deviations of predators from the predictions of foraging theories based on prey occurring in a discrete, homogeneous patch in an ecologically neutral background matrix (Kotliar \& Wiens 1990). As both predator and prey in this system exhibited a complex, highly connected hierarchy of patches, small changes in scale would change the variance structure of the system and result in large effects on prey encounter rates and the time a predator remains in a patch (Charnov 1976, Krebs 1978, Kotliar \& Wiens 1990). Predators in these types of systems need to use scale-dependent movement patterns that match the spatial scale of the environment (Fauchald 1999) rather than simply increasing turning rate in areas of high prey density and decreasing it in areas of low prey density - a pattern known as area restricted search (Grunbaum 1998). The high degree of match between the spacing of prey patches observed and the step lengths of fur seals we tracked suggests that fur seals have developed strategies to successfully exploit patchy juvenile pollock and likely other small schooling species. Despite a varied diet, the spatial scales of the distribution of predictable patches of prey such as juvenile pollock are critical in determining how female fur seals utilize the habitat surrounding their rookeries in the southeastern Bering Sea.

\section{LITERATURE CITED}

> Antonelis G, Sinclair E, Ream R, Robson B (1997) Interisland variation in the diet of female northern fur seals (Callorhinus ursinus) in the Bering Sea. J Zool 242: 435-451

Barange M (1994) Acoustic identification, classification and structure of biological patchiness on the edge of the Agulhas Bank and its relation to frontal features. S Afr J Mar Sci 14:333-347

> Benoit-Bird KJ (2009) Dynamic three-dimensional structure of thin zooplankton layers is impacted by foraging fish. Mar Ecol Prog Ser 396:61-76

Benoit-Bird KJ, Au WWL (2003) Prey dynamics affect foraging by a pelagic predator (Stenella longirostris) over a range of spatial and temporal scales. Behav Ecol Sociobiol 53:364-373

Benoit-Bird KJ, Au WWL (2006) Extreme diel horizontal migrations by a tropical nearshore resident micronekton community. Mar Ecol Prog Ser 319:1-14

Benoit-Bird KJ, Au WWL (2009) Cooperative prey herding by the pelagic dolphin, Stenella longirostris. J Acoust Soc Am 125:125-137

Benoit-Bird KJ, McManus MA (2012) Bottom-up regulation of a pelagic community through spatial aggregations. Biol Lett 8:813-816

> Benoit-Bird KJ, Kuletz K, Heppell S, Jones N, Hoover B (2011) Active acoustic examination of the diving behavior of murres foraging on patchy prey. Mar Ecol Prog Ser 443:217-235

Beyer JE (1995) Functional heterogeneity: using the interrupted poisson process (IPP) model unit in addressing how food aggregation may affect fish ration. ICES Council Meeting Papers, Copenhagen

Boyd II (1996) Temporal scales of foraging in a marine predator. Ecology 77:426-434

Call KA, Ream RR (2012) Prey selection of subadult male northern fur seals (Callorhinus ursinus) and evidence of dietary niche overlap with adult females during the breeding season. Mar Mamm Sci 28:1-15

Charnov EL (1976) Optimal foraging, the marginal value theorem. Theor Popul Biol 9:129-136

> Coachman L (1986) Circulation, water masses, and fluxes on the southeastern Bering Sea shelf. Cont Shelf Res 5: 23-108

Crist TO, Guertin DS, Wiens JA, Milne BT (1992) Animal movement in heterogeneous landscapes: an experiment with Eleodes beetles in shortgrass prairie. Funct Ecol 6: 536-544

> Davis CS, Flierl GR, Wiebe PH (1991) Micropatchiness, turbulence and recruitment in plankton. J Mar Res 49: 109-151

> De Robertis A (2002) Size-dependent visual predation risk and the timing of vertical migration: an optimization model. Limnol Oceanogr 47:925-933

> De Robertis A, McKelvey, DR, Ressler, PH (2010) Development and application of an empirical multifrequency method for backscatter classification. Can J Fish Aquat Sci 67:1459-1474

> Decker MB, Hunt GL Jr (1996) Foraging by murres (Uria spp.) at tidal fronts surrounding the Pribilof Islands, Alaska, USA. Mar Ecol Prog Ser 139:1-10

> Dekshenieks MM, Donaghay PL, Sullivan JM, Rines JEB, Osborn TR, Twardowski MS (2001) Temporal and spatial occurrence of phytoplankton thin layers in relation to physical processes. Mar Ecol Prog Ser 223:61-71

> Diner N (2001) Correction on school geometry and density: approach based on acoustic image simulation. Aquat Living Resour 14:211-222

> Edwards AM, Phillips RA, Watkins NW, Freeman MP and others (2007) Revisiting Lévy flight search patterns of wandering albatrosses, bumblebees and deer. Nature 449:1044-1048

Enright JT (1977) Diurnal vertical migration: adaptive significance and timing. Limnol Oceanogr 22:856-886

> Fauchald P (1999) Foraging in a hierarchical patch system. Am Nat 153:603-613

> Fauchald P (2009) Spatial interaction between seabirds and prey: review and synthesis. Mar Ecol Prog Ser 391:139-151 Fauchald P, Tveraa T (2006) Hierarchical patch dynamics 
and animal movement pattern. Oecologia 149:383-395

Fauchald P, Erikstad KE, Skarsfjord H (2000) Scale dependent predator-prey interactions: the hierarchical spatial distribution of seabirds and prey. Ecology 81:773-783

> Foote KG, Traynor JJ (1988) Comparison of walleye pollock target strength estimates determined from in situ measurements and calculations based on swimbladder form. J Acoust Soc Am 83:9-17

Fritz H, Said S, Weimerskirch H (2003) Scale-dependent hierarchical adjustments of movement patterns in a longrange foraging seabird. Proc R Soc Lond B Biol Sci 270: 1143-1148

Gentry RL, Holt JR (1986) Attendance behavior of northern fur seals. In: Gentry RL, Kooyman GL (eds) Fur seals: maternal strategies on land and at sea. Princeton University Press, Princeton, NJ, p 61-78

Gentry RL, Kooyman GL, Goebel ME (1986) Feeding and diving behavior of northern fur seals. In: Gentry RL, Kooyman GL (eds) Fur seals: maternal strategies on land and at sea. Princeton University Press, Princeton, NJ, p 61-78

Gentry RL, Pierson MO, Vladimirov VA (1998) Female foraging behavior: effects of continental shelf width. In: Gentry RL (ed) Behavior and ecology of the northern fur seal. Princeton University Press, Princeton, NJ, p 261-275

Girvetz EH, Greco SE (2007) How to define a patch: a spatial model for hierarchically delineating organism-specific habitat patches. Landscape Ecol 22:1131-1142

Goebel M, Bengtson J, DeLong R, Gentry R, Loughlin T (1991) Diving patterns and foraging locations of female northern fur seals. Fish Bull 89:171-179

Grünbaum D (1998) Using spatially explicit models to characterize foraging performance in heterogeneous landscapes. Am Nat 151:97-113

Haury LR, McGowan JA, Wiebe PH (1978) Patterns and processes in the time-space scales of plankton distributions. In: Steele JH (ed) Spatial pattern in plankton communities. Plenum Press, New York, NY, p 277-328

Hazel J (2009) Evaluation of fast-acquisition GPS in stationary tests and fine-scale tracking of green turtles. J Exp Mar Biol Ecol 374:58-68

Hickey J, Craighead F (1977) A census of seabirds on the Pribilof Islands. Environmental assessment of the Alaskan continental shelf: annual reports of principal investigators, Vol 2. NOAA, Boulder, CO, p 96-195

> Horne JK, Schneider DC (1995) Spatial variance in ecology. Oikos 74:18-26

Hunt G Jr, Schneider D (1987) Scale-dependent processes in the physical and biological environment of marine birds. In: Croxall JP (ed) Seabirds: feeding ecology and role in marine ecosystems. University Press, Cambridge, p 7-41

Ichihara T, Yoshido K (1972) Diving depth of northern fur seals in the feeding time. Sci Rep Whales Res Inst 24: $145-148$

- Ives AR, Kareiva P, Perry R (1993) Response of a predator to variation in prey density at three hierarchical scales: lady beetles feeding on aphids. Ecology 74:1929-1938

Johnson CJ, Parker KL, Heard DC, Gillingham MP (2002) Movement parameters of ungulates and scale-specific responses to the environment. J Anim Ecol 71:225-235

Kooyman GL, Gentry RL, Urquhart DL (1976) Northern fur seal diving behavior: a new approach to its study. Science 193:411-412

Kotliar NB, Wiens JA (1990) Multiple scales of patchiness and patch structure: a hierarchical framework for the study of heterogeneity. Oikos 59:253-260

Krebs JR (1978) Optimal foraging: decision rules for predators. In: Krebs JR, Davies NB (eds) Behavioural ecology, an evolutionary approach. Sinauer, Sunderland, MA, p 23-63

Kuhn CE, Tremblay Y, Ream RR, Gelatt TS (2010) Coupling GPS tracking with dive behaviour to examine the relationship between foraging strategy and fine-scale movements of northern fur seals. Endang Species Res 12: 125-139

Lasker R (1975) Field criteria for the survival of anchovy larvae: the relation between inshore chlorophyll maximum layers and successful first feeding. Fish Bull 73:453-462

Levin SA (1992) The problem of pattern and scale in ecology. Ecology 73:1943-1967

> Logerwell E, Hewitt R, Demer DA (1998) Scale-dependent spatial variance patterns and correlations of seabirds and prey in the southeastern Bering Sea as revealed by spectral analysis. Ecography 21:212-223

Loughlin TR, Bengtson JL, Merrick RL (1987) Characteristics of feeding trips of female northern fur seals. Can J Zool 65:2079-2084

Mackas DL, Denman KL, Abbott MR (1985) Plankton patchiness: biology in the physical vernacular. Bull Mar Sci 37 : 652-674

> Mason DM, Brandt SB (1996) Effects of spatial scale and foraging efficiency on the predictions made by spatiallyexplicit models of fish growth rate potential. Environ Biol Fishes 45:283-298

McIntosh NE (2011) Horizontal and vertical distribution of juvenile pollock (Theragra chalcogramma) in the southeastern Bering Sea. MSc thesis, Oregon State University, Corvallis, OR

> Mehlum F, Hunt GL Jr, Klusek Z, Decker MB (1999) Scaledependent correlations between the abundance of Brünnich's guillemots and their prey. J Anim Ecol 68:60-72

Mizobata K, Saitoh S, Wang J (2008) Interannual variability of summer biochemical enhancement in relation to mesoscale eddies at the shelf break in the vicinity of the Pribilof Islands, Bering Sea. Deep-Sea Res II 55: 1717-1728

> Morales JM, Haydon DT, Frair J, Holsinger KE, Fryxell JM (2004) Extracting more out of relocation data: building movement models as mixtures of random walks. Ecology 85:2436-2445

> Nams VO (2005) Using animal movement paths to measure response to spatial scale. Oecologia 143:179-188

Nordstrom CA, Battaile BC, Cotté C, Trites AW (2013) Foraging locations of lactating fur seals are structured by thermocline depths and submesoscale fronts in the eastern Bering Sea. Deep-Sea Res II 88-89:78-96

O'Neill RV, Gardner RH, Milne BT, Turner MG, Jackson B (1991) Heterogeneity and spatial hierarchies. In: Kolasar J, Pickett STA (eds) Ecological heterogeneity. SpringerVerlag, New York, NY, p 85-96

Orians G, Pearson N (1979) On the theory of central place foraging. In: Horn D, Stairs G, Mitchell R (eds) Analysis of ecological systems. Ohio State University Press, Columbus, OH, p 155-177

Pearcy WG, Nemoto T, Okiyama M (1979) Mesopelagic fishes of the Bering Sea and adjacent northern North Pacific Ocean. J Oceanogr 35:127-135

Ressler PH, De Robertis A, Warren JD, Smith JN, Kotwicki S (2012) Developing an acoustic survey of euphausiids to understand trophic interactions in the Bering Sea ecosystem. Deep-Sea Res II 65-70:184-195 
Robson BW, Goebel ME, Baker JD, Ream RR and others (2004) Separation of foraging habitat among breeding sites of a colonial marine predator, the northern fur seal (Callorhinus ursinus). Can J Zool 82:20-29

Rose GA, Leggett WC (1990) The importance of scale to predator-prey spatial correlations: an example of Atlantic fishes. Ecology 71:33-43

Russell RW, Hunt GL Jr, Coyle KO, Cooney RT (1992) Foraging in a fractal environment: spatial patterns in a marine predator-prey system. Landscape Ecol 7:195-209

Schneider D, Piatt J (1986) Scale-dependent correlation of seabirds with schooling fish in a coastal ecosystem. Mar Ecol Prog Ser 32:237-246

Sigler MF, Kuletz KJ, Ressler PH, Friday NA, Wilson CD, Zerbini AN (2012) Marine predators and persistent prey in the southeast Bering Sea. Deep Sea Res II 65-70: 292-303

Sih A (1982) Optimal patch use: variation in selective pressure for efficient foraging. Am Nat 120:666-685

Sims DW, Quayle VA (1998) Selective foraging behaviour of basking sharks on zooplankton in a small-scale front. Nature 393:460-464

Sims DW, Southall EJ, Humphries NE, Hays GC and others (2008) Scaling laws of marine predator search behaviour. Nature 451:1098-1102

Sinclair E, Stabeno P (2002) Mesopelagic nekton and associated physics of the southeastern Bering Sea. Deep-Sea Res II 49:6127-6145

Sinclair E, Loughlin T, Pearcy W (1994) Prey selection by northern fur seals (Callorhinus ursinus) in the eastern Bering Sea. Fish Bull 92:144-156

Sinclair E, Vlietstra L, Johnson D, Zeppelin T and others (2008) Patterns in prey use among fur seals and seabirds in the Pribilof Islands. Deep-Sea Res II 55:1897-1918

Sinclair E, York A, Antonelis G (2011) Otolith size and location in digestive tracts of northern fur seals (Callorhinus ursinus): implications for dietary interpretations. Mar Mamm Sci 27:421-430

Springer AM, McRoy CP, Flint MV (1996) The Bering Sea Green Belt: shelf-edge processes and ecosystem production. Fish Oceanogr 5:205-223

Steele JH (1978) Spatial pattern in plankton communities. In: NATO Conference Series, Marine Sciences IV, Vol 3. Plenum Press, New York, NY, p 470

Editorial responsibility: Peter Corkeron, Woods Hole, Massachusetts, USA
Tiselius P, Jonsson PR, Verity PG (1993) A model evaluation of the impact of food patchiness on foraging strategy and predation risk in zooplankton. Bull Mar Sci 53: $247-264$

Towell RG, Ream R (2011) 2011 northern fur seal pup production estimate on Bogoslof Island, Alaska. National Marine Mammal Laboratory Report, Seattle, WA

Towell RG, Ream R, Bengston J, Sterling J (2011) 2010 northern fur seal pup production and adult male counts on the Pribilof Islands, Alaska. National Marine Mammal Laboratory Report, Seattle, WA

Traynor JJ (1996) Target-strength measurements of walleye pollock (Theragra chalcogramma) and Pacific whiting (Merluccius productus). ICES J Mar Sci 53:253-258

> Weimerskirch H, Pinaud D, Pawlowski F, Bost CA (2007) Does prey capture induce area-restricted search? A finescale study using GPS in a marine predator, the wandering albatross. Am Nat 170:734-743

Wiens JA (1989) Spatial scaling in ecology. Funct Ecol 3: 385-397

Wiese FK, Wiseman WJ, Van Pelt TI (2012) Bering Sea linkages. Deep-Sea Res II 65:2-5

Wilson RP, Liebsch N, Davies IM, Quintana F and others (2007) All at sea with animal tracks; methodological and analytical solutions for the resolution of movement. Deep-Sea Res II 54:193-210

With KA (1994) Using fractal analysis to assess how species perceive landscape structure. Landscape Ecol 9:25-36

Worton BJ (1989) Kernel methods for estimating the utilization distribution in home-range studies. Ecology 70 : 164-168

Wu J, Loucks OL (1995) From balance of nature to hierarchical patch dynamics: a paradigm shift in ecology. Q Rev Biol 70:439-466

Zeppelin TK, Orr AJ (2010) Stable isotope and scat analyses indicate diet and habitat partitioning in northern fur seals Callorhinus ursinus across the eastern Pacific. Mar Ecol Prog Ser 409:241-253

Zeppelin T, Ream R (2006) Foraging habitats based on the diet of female northern fur seals (Callorhinus ursinus) on the Pribilof Islands, Alaska. J Zool 270:565-576

Zhang ZQ, Sanderson JP (1993) Spatial scale of aggregation in three acarine predator species with different degrees of polyphagy. Oecologia 96:24-31

Submitted: July 20, 2012; Accepted: November 30, 2012 Proofs received from author(s): March 18, 2013 